\title{
Down-flow and horseshoe vortex characteristics of sediment embedded bridge piers
}

\section{Journal Article}

\section{Author(s):}

Unger, Jens; Hager, Willi $\mathrm{H}$.

Publication date:

2007-01

Permanent link:

https://doi.org/10.3929/ethz-b-000157846

Rights / license:

In Copyright - Non-Commercial Use Permitted

Originally published in:

Experiments in Fluids 42(1), https://doi.org/10.1007/s00348-006-0209-7 


\title{
Down-flow and horseshoe vortex characteristics of sediment embedded bridge piers
}

\author{
Jens Unger · Willi H. Hager
}

Received: 31 March 2006/Revised: 11 September 2006/ Accepted: 14 September 2006/ Published online: 3 November 2006

(C) Springer-Verlag 2006

\begin{abstract}
The flow around bridge structures is a recent research topic, given the significance of bridges as basic engineering infrastructures. This study investigates the internal flow features around circular bridge piers by Particle Image Velocimetry applied both in the horizontal and vertical planes and therefore allowing for a quasi-spatial visualization of the velocity field. The temporal evolution of the vertical deflected flow at the pier front and the horseshoe vortex inside the increasing scour hole were explored resulting in the velocity and vorticity profiles. This work, therefore, provides novel insight into the complex and fascinating two-phase flow around circular bridge piers placed in loose sediment and provides an experimental data basis for advanced numerical simulation.
\end{abstract}

\section{List of symbols}

$a_{v} \quad$ longer vortex ellipse axis

$b_{v} \quad$ shorter vortex ellipse axis

$B \quad$ channel width

$d_{50} \quad$ median sediment size

$d_{v} \quad=\left(a_{v}+b_{v}\right) / 2$ median vortex diameter

$D \quad$ pier diameter

$\mathrm{F}_{d} \quad=V_{o} /\left(\mathrm{g}^{\prime} d_{50}\right)^{1 / 2}$ densimetric particle Froude number of the approach flow

$\mathrm{F}_{t} \quad=V_{o} / V_{t}$ threshold Froude number

J. Unger $(\bowtie) \cdot$ W. H. Hager

VAW, ETH Zurich, 8092 Zurich, Switzerland

e-mail: unger@vaw.baug.ethz.ch

W. H. Hager

e-mail: hager@vaw.baug.ethz.ch $\mathrm{g}^{\prime} \quad=\left[\left(\rho_{s}-\rho\right) / \rho\right] \mathrm{g}$ reduced gravitational acceleration

$h_{o} \quad$ approach flow depth

$Q \quad$ discharge

$R^{2} \quad$ correlation coefficient

$\mathrm{R}_{D} \quad=\left(V_{o} D\right) / v$ pier Reynolds number

$t$ time

$t_{0} \quad$ time to the formation of the horseshoe vortex

$t_{R} \quad=z_{R} /\left[\sigma^{1 / 3}\left(\mathrm{~g}^{\prime} d_{50}\right)^{1 / 2}\right]$ reference time

$T_{0} \quad=t_{0} / t_{R}$ relative time to the formation of horseshoe vortex

$T_{S} \quad=t / t_{R}$ relative scour time

$v_{x}, v_{y}, v_{z} \quad$ velocity components

$v_{x v} \quad$ horizontal horseshoe vortex velocity component

$v_{x v, \max }$ maximum horizontal horseshoe vortex velocity component

$v_{x v}$ min minimum horizontal horseshoe vortex velocity component

$v_{z f} \quad$ vertical down-flow velocity component

$v_{z f \text {, max }}$ maximum vertical down-flow velocity component

$v_{z r, \max }$ maximum vertical surface roller velocity component

$V_{o} \quad$ approach flow velocity

$V_{t} \quad$ threshold velocity

$V_{x v} \quad=v_{x v} / v_{x v}$, min normalized horizontal horseshoe vortex velocity

$V_{z f} \quad=v_{z f} d v_{z f, \text { max }}$ normalized vertical down-flow velocity component

$x, y, z \quad$ coordinates in space

$x_{v} \quad$ horizontal distance between pier front and horseshoe vortex centre 
$X_{v} \quad=x_{v} / z_{R}$ normalized horizontal distance between pier front and horseshoe vortex centre

$z_{f 0} \quad$ distance between the stagnation point and the original sediment bed elevation

$z_{f \text {, max }} \quad$ distance between the original sediment bed elevation and the position of the maximum vertical down-flow velocity

$z_{R} \quad=\left(D^{2} h_{o}\right)^{1 / 3}$ reference length

$z_{r, \max } \quad$ depth of the maximum vertical surface roller velocity

$z_{S} \quad$ scour depth

$z_{S v} \quad$ scour depth below the horseshoe vortex centre

$z_{v 0} \quad$ distance between original sediment bed elevation and horseshoe vortex centre

$\dot{Z}_{v} \quad=\left(z+z_{S v}\right)$ transformed vertical coordinate of the velocity profile through the horseshoe vortex centre

$\dot{Z}_{v x}$, min vertical distance between the instantaneous sediment surface elevation and the minimum horseshoe vortex velocity

$z_{y}=0 \quad$ scour depth in the channel axis

$Z_{f} \quad=\left(z_{S}+z\right) /\left(z_{S}+z_{f 0}\right)$ normalized vertical down-flow coordinate

$Z_{f, \max } \quad$ normalized depth of the maximum vertical down-flow velocity

$Z_{S} \quad=z_{S} / z_{R}$ normalized scour depth

$Z_{S v} \quad=z_{S v} / z_{R}$ normalized scour depth below the horseshoe vortex centre

$Z_{v 0} \quad=z_{v 0} / z_{R}$ normalized distance between original sediment bed elevation and horseshoe vortex centre

$\dot{Z}_{v} \quad=\dot{z}_{v} /\left(z_{S v}+z_{v 0}\right)$ transformed and normalized vertical coordinate of the velocity profile through the horseshoe vortex centre

$\dot{Z}_{v x, \min }=\dot{z}_{v x, \min } /\left(z_{S v}+z_{v 0}\right)$ normalized vertical distance between the instantaneous sediment surface elevation and the minimum horseshoe vortex velocity

$\gamma \quad=0.025$ constant

$\rho \quad$ density

$\sigma=\left(d_{84} / d_{16}\right)^{1 / 2}$ sediment non-uniformity

$\phi \quad$ angle measured from the mean flow direction

$v \quad$ kinematic viscosity

\section{Introduction}

The flow deflected by sediment embedded bridge piers causes scour at its foundations. Scour may endanger the stability of the complete bridge structure. In bridge hydraulics circular-shaped pier foundations are commonly used. Due to the similar flow structures of airflow around circular bodies in wind tunnels, the basic researches concern flow visualization in aerodynamics. Thwaites (1960) or Batchelor (1967) reviewed the earlier aerodynamic studies relating to the flow field around cylindrical structures. Therein, the main flow features involve a vertically deflected flow along the cylinder front, a horseshoe vortex system upstream of the cylinder, a flow separation beside the cylinder and a wake zone downstream of it.

Baker (1979, 1980, 1985) investigated the detailed characteristics of the horseshoe vortex around a circular cylinder embedded in a horizontal fixed bed. His 1979 and 1980 works refer to the laminar and turbulent boundary layer separations, respectively. The pressure distribution beneath the horseshoe vortex system was measured and the horseshoe vortex position was determined experimentally. Baker (1985) described the geometric position of points of zero shear stres$\mathrm{s}$-along the separation line-and of the maximum shear stress beneath the main horseshoe vortex. He observed for all flow conditions a horseshoe vortex system consisting of at least two vortices. In contrast, Eckerle and Langston (1987) found under well-defined flow conditions the existence of a single main horseshoe vortex and one saddle point in the streamwise plane of symmetry. Their results were based on a detailed investigation of the pressure and the velocity distribution around a circular cylinder using a five-hole Pitot-tube.

Melville and Raudkivi (1977) presented a first extension of the aerodynamics experiments; they analyzed water-flow over a mobile sediment bed for different fixed scour stages. The flow patterns were traced using the hydrogen-bubble method. The velocity magnitudes and turbulence intensities within the scour hole were measured with a DISA Hot-Film anemometer. Before starting measurements, the loose sediment bed was coated with plaster to retain three stages of scour: (1) the initial flat bed, (2) scoured bed after $30 \mathrm{~min}$ and (3) equilibrium scour conditions. The main results concerned the flow patterns in vertical and horizontal planes, the turbulence intensity and the bed shear stress distribution. Additionally, this study indicates the existence of a non-scour inducing single horseshoe vortex during all three stages.

Based on this investigation a number of mainly experimental studies were conducted to characterise the specific flow features around a sediment embedded bridge pier inside the scour hole. 
Qadar (1981) explored the interactions between the horseshoe vortex and the temporal increase of scour depth. Dargahi (1989) presented an extensive study containing the temporal evolution of the main flow features around circular bridge piers placed in a fixed sediment bed. He also visualized the flow field using air bubbles. Additionally the bed shear stresses were measured with a Preston tube. Dargahi detected the simultaneous presence of various horseshoe vortices upstream of the leading pier front. Ahmed and Rajaratnam (1998) and Sarker (1998) investigated the down-flow characteristics for a mobile sediment bed with a Preston tube and Acoustic Doppler Velocimetry (ADV), respectively. Ahmed and Rajaratnam (2000) extended this work to rectangular bridge abutments, a topic not considered herein.

Graf and Yulistiyanto (1998) and later Graf and Istiarto (2002) determined experimentally the velocity, the turbulence intensity, the turbulent kinetic energy and the bed shear stress distributions around a sediment embedded circular bridge pier. Therein, an ADV Profiler developed by Lhermitte and Lemmin (1994) was used to measure the velocity components in a vertical profile for fixed and mobile bed configurations. They detected a strong horseshoe vortex upstream from the pier and downstream of it a flow recirculation toward the water surface. Further, high turbulence intensities and Reynolds shear stresses were found close to the pier footing and in the pier wake zone. Barbhuiya and Dey (2004) obtained similar results from a semicircular pier arrangement placed at the channel sidewall.

A detailed analysis of the horseshoe vortex characteristic presented by Muzzammil and Gangadharaiah (2003) was discussed by Unger und Hager (2005b). The vortex size, vortex velocity and vortex strength were determined in terms of the relevant hydraulic and geometric parameters and the temporal scour hole evolution. Muzzammil and Gangadharaiah proposed a linear increase of the temporal vortex size and a complex power function describing the temporal evolution of the vortex velocity and vortex strength. All these experimental researches used intrusive and noninstantaneous techniques. These disturb the turbulent flow patterns considerably, in addition to the point-wise readings not allowing to record the unsteady flow patterns and the coherent flow structures. Therefore, some isolated studies recorded the flow field around bridge piers with Particle Image Velocimetry (PIV), a nonintrusive and instantaneous velocity measuring method (Pogozelski et al. 1997; Johnson and Ting 2003). Due to the test setup the latter study was limited to (1) two horizontal planes 10 and $40 \mathrm{~mm}$ above smooth and fixed beds and (2) a viewing area of only $90 \mathrm{~mm}^{2}$.
The present research aims at a detailed temporal description of the horseshoe vortex and the downflow characteristics of sediment embedded circular bridge piers using PIV. These flow features govern the scour advance. In contrast to most other studies a generalized approach was selected to determine the velocity distribution. The knowledge of these coherent plane flow structures allows estimating the acting bed-shear stresses, a topic dealt with in a forthcoming study.

\section{Experiments}

\subsection{Physical model}

Figure 1 shows the rectangular VAW scour channel, allowing for a maximum water depth of $0.40 \mathrm{~m}$; its width is $1.00 \mathrm{~m}$ and the maximum water discharge $130 \mathrm{l} / \mathrm{s}$. A horizontal mobile sediment bed $6 \mathrm{~m}$ long was placed in this scour channel (Hager et al. 2002). Two sediments were used: (1) an uniform sand of median size $d_{50}=1.14 \mathrm{~mm}$ and a sediment non-uniformity $\sigma=\left(d_{84} / d_{16}\right)^{1 / 2}=1.18$, and (2) a sand mixture with $d_{50}=5.00 \mathrm{~mm}$ and $\sigma=2.29$. Table 1 summarizes the experimental conditions of this study. The semicircular plexiglass piers were placed at the glassed channel sidewall, to allow for optical flow visualization. Additional tests demonstrated that the half channel arrangement is identical to the full setup, provided the pier diameter is larger than $10 \%$ of the channel width, to inhibit effects of the boundary layer along the glass wall (Appendix 1; Unger and Hager 2006a; Unger 2006). The present research considered only clear water approach flow conditions described by a threshold Froude number of $0.60 \leq \mathrm{F}_{t}=V_{o} / V_{t} \leq 0.98$ with $V_{o}$ as the approach flow velocity and $V_{t}$ as the threshold velocity (Hager and Oliveto 2002).

The preparation of an experimental run includes the following works (Fig. 1): (1) Placement of pier model 8, (2) Grading horizontally the sediment bed, (3) Preadjusting the water level to an elevation without any sediment movement by using the flap gate (10, (4) Starting the pump (1), (5) Slow increase of discharge to test value without any sediment movement, (6) Lowering the tailwater depth to incipient sediment entrainment at the pier sides using the flap gate (10, (7) Set time $t=0$ and (8) Further lowering tailwater level to the selected test conditions (Hager et al. 2002). Normally the scour and the water surface topographies and the $2 \mathrm{D}$ velocity vectors were measured at times $t=60 ; 180 ; 360 ; 600 ; 1,200 ; 2,400 ; 3,600 ; 7,200 ; 14,440$; 28,800 and $86,400 \mathrm{~s}$. 


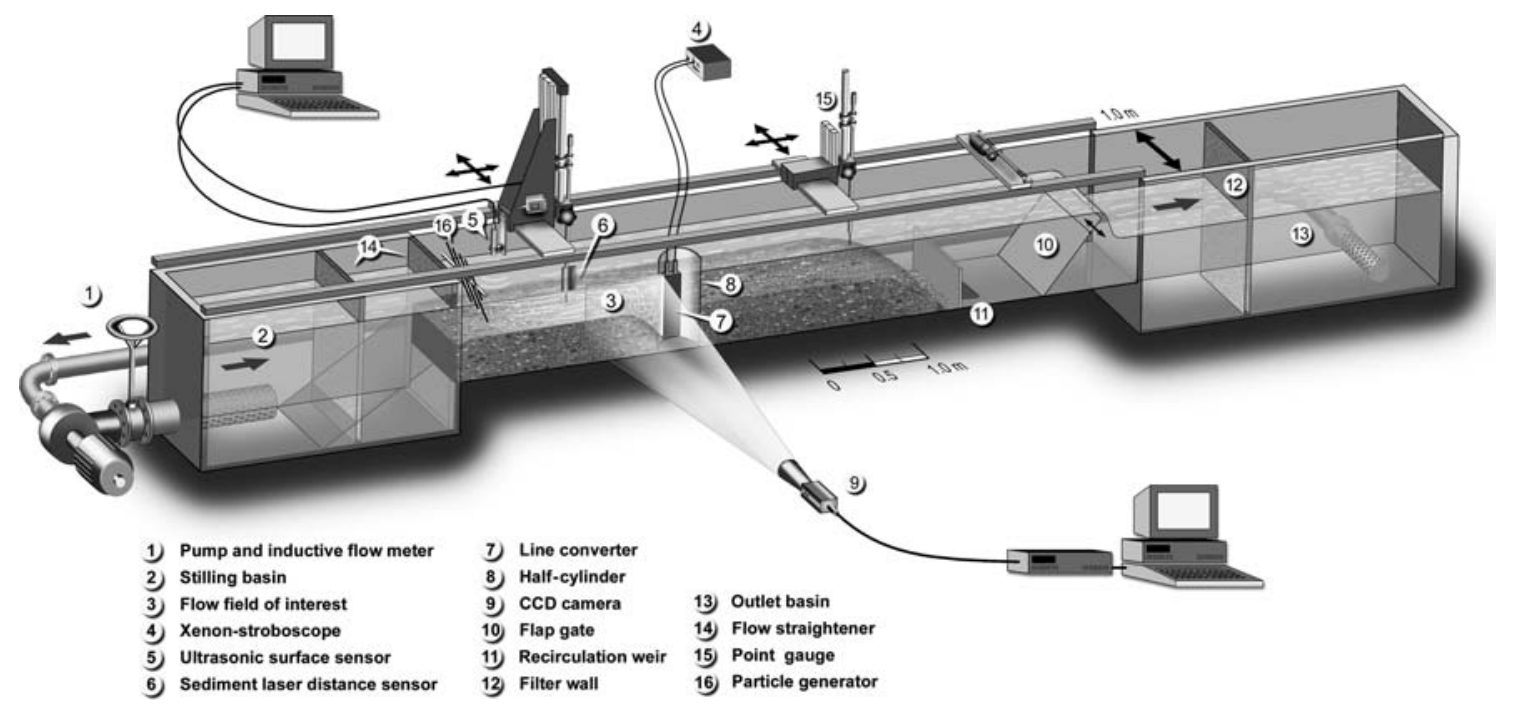

Fig. 1 VAW scour channel including PIV setup

Table 1 Test conditions of Unger (2006)

\begin{tabular}{|c|c|c|c|c|c|c|c|c|c|c|c|c|c|}
\hline$N r$ & $d_{50}(\mathrm{~mm})$ & $\sigma(-)$ & $D(\mathrm{~m})$ & $Q\left(\mathrm{~m}^{3} / \mathrm{s}\right)$ & $h_{o}(\mathrm{~m})$ & $V_{o}(\mathrm{~m} / \mathrm{s})$ & $\mathrm{F}_{o}(-)$ & $\mathrm{F}_{d}(-)$ & $\mathrm{F}_{d i}(-)$ & $\mathrm{F}_{d i, \beta}(-)$ & $\mathrm{F}_{t}(-)$ & $\mathrm{R}_{D} \times 10^{-5}(-)$ & $h_{o} / D(-)$ \\
\hline A1 & 5.00 & 2.29 & 0.457 & 0.050 & 0.096 & 0.521 & 0.537 & 1.83 & 3.43 & 1.69 & 0.53 & 2.357 & 0.210 \\
\hline A2 & 5.00 & 2.29 & 0.457 & 0.050 & 0.072 & 0.694 & 0.826 & 2.44 & 3.29 & 1.62 & 0.74 & 3.142 & 0.158 \\
\hline A3 & 5.00 & 2.29 & 0.457 & 0.080 & 0.132 & 0.606 & 0.533 & 2.13 & 3.60 & 1.78 & 0.59 & 2.742 & 0.289 \\
\hline A4 & 5.00 & 2.29 & 0.457 & 0.080 & 0.091 & 0.879 & 0.930 & 3.09 & 3.41 & 1.68 & 0.91 & 3.978 & 0.199 \\
\hline A5 & 5.00 & 2.29 & 0.457 & 0.110 & 0.190 & 0.579 & 0.424 & 2.04 & 3.80 & 1.87 & 0.54 & 2.620 & 0.416 \\
\hline A6 & 5.00 & 2.29 & 0.457 & 0.110 & 0.125 & 0.880 & 0.795 & 3.09 & 3.57 & 1.76 & 0.87 & 3.982 & 0.274 \\
\hline B1 & 5.00 & 2.29 & 0.260 & 0.050 & 0.080 & 0.625 & 0.706 & 2.20 & 3.34 & 1.87 & 0.66 & 1.609 & 0.308 \\
\hline B2 & 5.00 & 2.29 & 0.260 & 0.050 & 0.058 & 0.862 & 0.963 & 3.03 & 3.18 & 1.78 & 0.95 & 2.219 & 0.250 \\
\hline B3 & 5.00 & 2.29 & 0.260 & 0.080 & 0.133 & 0.602 & 0.527 & 2.11 & 3.61 & 2.02 & 0.59 & 1.548 & 0.512 \\
\hline B4 & 5.00 & 2.29 & 0.260 & 0.080 & 0.090 & 0.889 & 0.946 & 3.12 & 3.40 & 1.90 & 0.92 & 2.288 & 0.346 \\
\hline B5 & 5.00 & 2.29 & 0.260 & 0.110 & 0.160 & 0.688 & 0.549 & 2.42 & 3.70 & 2.07 & 0.65 & 1.770 & 0.615 \\
\hline B6 & 5.00 & 2.29 & 0.260 & 0.110 & 0.130 & 0.849 & 0.749 & 2.97 & 3.59 & 2.01 & 0.83 & 2.178 & 0.500 \\
\hline $\mathrm{C} 1$ & 1.14 & 1.18 & 0.457 & 0.050 & 0.150 & 0.333 & 0.275 & 2.46 & 3.33 & 1.79 & 0.74 & 1.508 & 0.328 \\
\hline $\mathrm{C} 2$ & 1.14 & 1.18 & 0.457 & 0.050 & 0.120 & 0.417 & 0.384 & 3.07 & 3.22 & 1.74 & 0.95 & 1.885 & 0.263 \\
\hline $\mathrm{C} 3$ & 1.14 & 1.18 & 0.457 & 0.070 & 0.190 & 0.368 & 0.270 & 2.71 & 3.44 & 1.86 & 0.79 & 1.667 & 0.416 \\
\hline $\mathrm{C} 4$ & 1.14 & 1.18 & 0.457 & 0.070 & 0.160 & 0.438 & 0.349 & 3.22 & 3.36 & 1.81 & 0.96 & 1.980 & 0.350 \\
\hline C5 & 1.14 & 1.18 & 0.457 & 0.025 & 0.080 & 0.313 & 0.353 & 2.30 & 3.03 & 1.63 & 0.76 & 1.414 & 0.175 \\
\hline C6 & 1.14 & 1.18 & 0.457 & 0.025 & 0.065 & 0.385 & 0.482 & 2.83 & 2.93 & 1.58 & 0.97 & 1.740 & 0.142 \\
\hline D1 & 1.14 & 1.18 & 0.260 & 0.050 & 0.166 & 0.301 & 0.236 & 2.22 & 3.38 & 2.03 & 0.66 & 0.775 & 0.638 \\
\hline D2 & 1.14 & 1.18 & 0.260 & 0.050 & 0.126 & 0.397 & 0.357 & 2.92 & 3.24 & 1.95 & 0.90 & 1.022 & 0.485 \\
\hline D3 & 1.14 & 1.18 & 0.260 & 0.070 & 0.231 & 0.303 & 0.201 & 2.23 & 3.54 & 2.12 & 0.63 & 0.780 & 0.888 \\
\hline D4 & 1.14 & 1.18 & 0.260 & 0.070 & 0.182 & 0.385 & 0.288 & 2.83 & 3.42 & 2.05 & 0.83 & 0.990 & 0.700 \\
\hline D5 & 1.14 & 1.18 & 0.260 & 0.025 & 0.088 & 0.284 & 0.306 & 2.09 & 3.07 & 1.84 & 0.68 & 0.731 & 0.338 \\
\hline D6 & 1.14 & 1.18 & 0.260 & 0.025 & 0.064 & 0.391 & 0.493 & 2.88 & 2.93 & 1.75 & 0.98 & 1.006 & 0.246 \\
\hline
\end{tabular}

Note: $\mathrm{F}_{o}=V_{o} /\left(\mathrm{g} h_{o}\right)^{1 / 2}$ is the approach flow Froude number, $\mathrm{F}_{d i}=V_{i} /\left(\mathrm{g}^{\prime} d_{50}\right)^{1 / 2}$ is the densimetric Froude number for general sediment entrainment and $\mathrm{F}_{d i, \beta}=V_{i, \beta} /\left(\mathrm{g}^{\prime} d_{50}\right)^{1 / 2}$ the densimetric Froude number for sediment entrainment at a pier, according to Hager and Oliveto (2002)

\subsection{Instrumentation}

The sediment and water surface topographies were recorded using a combined unit consisting of a Laser Distance Sensor (LDS) (6) to scan the sediment surface and an Ultra-Sonic Sensor (USS) (5) to scan simulta- neously the water surface (Fig. 1). The LDS/USS unit was mounted on a high precision carriage for displacement in all three space directions. The accuracy of both components was $\pm 0.5 \mathrm{~mm}$. The bed topography was measured in addition to the PIV tests. Experiments were stopped at the time of interest $t$ by 
increasing the tailwater depth. The sediment topography was then scanned below water. Preliminary observations indicated that experiments are repeatable when scour progress is stopped by a tailwater increase instead of discharge reduction below the sediment entrainment limit (Hager et al. 2002).

A planar PIV setup was implemented to measure the velocity vector fields simultaneously and nonintrusive. The flow field was measured both in different elevated horizontal layers around the bridge pier, and in vertical layers upstream of the pier parallel to the approach flow direction. For the plan view observations, the water surface was covered with a thin plexiglass-plate to inhibit optical problems with surface waves. It was demonstrated that this addition does not affect the flow (Unger and Hager 2005a).

According to Fig. 1 the PIV system consists of a flashed Xenon-stroboscope (4) to illuminate the flow field (3) using a fibre-optic line-converter (7). The external Programmable Timing Unit (PTU) synchronized the exposure of the progressive scan monochrome CCD camera (9) with the stroboscope flash. The first flash was released just before the interline transfer started and the second flash thereafter. The pulse separation time was altered between 4 and $10 \mathrm{~ms}$ depending on the approach flow velocity (Raffel et al. 1998). A frame grabber board acquired the images at a data rate of up to $130 \mathrm{MB} / \mathrm{s}$. The raw images were captured in the RAM of the PIV computer in real time and stored on the hard disk afterwards. Each pair of this double frame single exposure images allowed calculating the velocity vector field by a cross-correlation algorithm. Normally, ten double-frame images were averaged over $1 / 3 \mathrm{~s}$, resulting from a preliminary analysis of the optimum recording time. For less data, the averaging process becomes inaccurate, whereas the data handling is complicated for a larger data number. Except for the very beginning of sediment entrainment during which the scour advance is relatively fast, flow conditions between two data recording sequences are quasi-steady. This is also mirrored by the logarithmic scour advance in time. With a maximum vertical bed evolution of some $0.15 \mathrm{~m} / 60 \mathrm{~s}=(1 / 400) \mathrm{m} / \mathrm{s}$, the corresponding change of the bed elevation is smaller than $1 \mathrm{~mm}$. The camera frame rate was $60 \mathrm{~Hz}$ with a time resolution of the PIV setup of $30 \mathrm{~Hz}$. The magnification factor varied between 0.015 and 0.025 resulting in a constantly spaced velocity vector mesh of some $5-10 \mathrm{~mm}$. The used tracer particles had a diameter of $0.5 \mathrm{~mm}$, a density of $1,008 \mathrm{~kg} / \mathrm{m}^{3}$ and a spherical shape because of underwater pelletizing. The flow was seeded using a hose pump and four intake nozzles some $3 \mathrm{~m}$ upstream from the pier to ensure homogeneous particle distribution.

There were no problems with the reflection of sediment particles because (1) a masked and high-pass filtered image was used, and (2) normally ten doubleframe single exposure images were taken and averaged. Singular incorrect image pairs were dropped. A detailed description of the used PIV setup is given by Unger und Hager (2006b).

\subsection{Flow field}

A characteristic example of the flow field close to the channel symmetry axis at $y=30 \mathrm{~mm}$ is shown in Fig. 2, for times $t=60,2,400,7,200$, and 86,400 s (run D1). At time $t=60 \mathrm{~s}$ no scour has yet occurred, because scour starts always at an angle $\phi$ of about $75^{\circ}$ from the channel axis (Oliveto and Hager 2002). The flow upstream from the pier at $x / h_{o} \leq-0.75$ is relatively uniform and nearly unaffected by the presence of the pier, due to the constantly spaced and parallel streamlines. Closer to the leading pier front, at $-0.75<x / h_{o}<-$ 0.25 , the flow decelerates but the velocity profile preserves its logarithmic shape. Toward the pier, the flow is strongly deflected in the vertical direction, resulting in two vertical jets directly at the pier front starting from the stagnation point. The upper jet, the so-called up-flow, is directed to the water surface whereas the lower jet, the down-flow, towards the sediment surface. The up-flow induces a surface recirculation and the down-flow is deflected against the main flow direction resulting finally in the so-called initial vortex close the sediment surface at $x / h_{o} \approx-0.40$.

At $t=2,400 \mathrm{~s}$, the scour zone has expanded from the pier sides to the channel axis; all flow features are conserved except for the initial vortex. In this flow phase, the down-flow is completely deflected in the transverse direction after having reached the sediment surface. The scour progresses then continuously and the horseshoe vortex is developed. In its initial stage at $t=7,200 \mathrm{~s}$ it consists of a single vortex located above the rim inside the scour hole. At $t=86,400 \mathrm{~s}$ both the vortex diameter and the maximum vorticity have continuously increased. Again, the approach flow, the down- and the up-flow, the stagnation point as well as the surface recirculation conserve their structure, independent from the temporal scour evolution. Due to the small hydraulic load of run D1, only one single horseshoe vortex develops and its evolution is relative slow. For larger hydraulic loads, considerably less time is required and the horseshoe vortex system is composed of a primary plus one or even more secondary vortices (Unger 2006). 

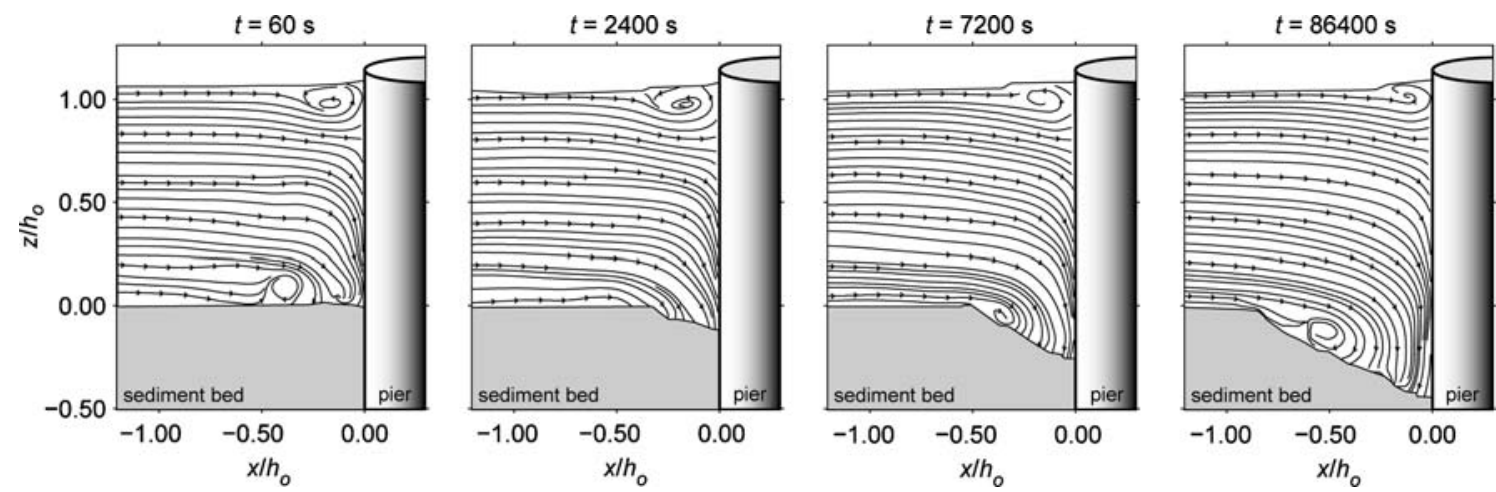

Fig. 2 Streamline plots of the flow in the channel symmetry axis at various times $t$ (run D1)

An example of the developing horizontal flow fields is shown in Fig. 3. It refers to the hydraulic conditions of Fig. 2. The streamlines in two different planes are plotted, namely (1) at $Z_{S}=z_{S} /\left(D^{2} h_{o}\right)^{1 / 3}=+0.50$ (with $h_{o}$ as the approach flow depth and $D$ as the pier diameter), corresponding to an elevation $z_{S}=(2 / 3) h_{o}$ above the original sediment surface, and (2) close to the original sediment surface at an elevation of $z_{S}=4 \mathrm{~mm}$, thus roughly at $Z_{S}=0$. Additionally, the dimensionless scour hole topography with the same scaling is plotted for both times. At depth $Z_{S}=+0.50$ the flow field is similar for all times. Upstream of the pier in the region $x / h_{o}<-0.75$ the flow is again relative uniform except for a minor flow deflection in the transverse channel direction. Closer to the pier front this deflection becomes more distinct because of a stronger streamline curvature. The velocity along the pier perimeter increases to its maximum at an angle of $\phi \approx 75^{\circ}$ resulting in sediment entrainment in this region. Simultaneously, the pressure decreases due to the velocity increase with the minimum value also at $\phi$ $\approx 75^{\circ}$. Beyond this point in the region $90^{\circ} \leq \phi \leq 120^{\circ}$, the flow separates from the pier due to the well-known pressure increase in the pier wake zone (Schlichting and Gersten 1997). With a pier Reynolds number $\mathrm{R}_{D}=\left(V_{o} D\right) / v$ between $5 \times 10^{4}$ and $3.5 \times 10^{6}$ (with $v$ as the kinematic viscosity) for the present experiments, the geometric position of the pressure minimum and the separation point are subject to turbulent fluctuations because of the permanent switch between the laminar and the turbulent separation patterns (Achenbach 1968). Downstream from the separation point extends the turbulent wake zone.

In the plane $Z_{S}=0$ the flow is more complex than in higher elevations (Fig. 3). At $t=60 \mathrm{~s}$ the flow in the entire region is strongly deflected in the transverse direction whereas at $t=86,400 \mathrm{~s}$ this phenomenon develops closer to the pier. At both times the instan- taneous scour circumference generates a separation line. The flow along the pier perimeter is accelerated as time progresses, with the detachment point moving slowly downstream the pier perimeter, similar to the Coanda effect (Unger and Hager 2006b).

Figure 3 shows in addition the temporal evolution of the scour topography. The scour zone starts at an angle of $\phi \approx 75^{\circ}$ for $t=60 \mathrm{~s}$. The sediment deposition zone in this early scour stage is close to the pier immediately downstream from the scour zone. With increasing time the maximum scour depth migrates toward the pier front, and the scour hole expands laterally. At $t=86,400 \mathrm{~s}$, the maximum scour depth has reached the pier front, and the sediment deposition zone has successively expanded downstream beyond the pier end. In the further scour process, the maximum scour depth and the scour expansion increase logarithmically with time (Melville and Coleman 2000; Oliveto and Hager 2005).

\section{Test results}

\subsection{Principal flow features}

According to Figs. 2 and 3 and from a detailed data analysis the following four principal flow patterns were identified (Unger and Hager 2006b):

- Phase 1: At scour beginning, a small non-scouring initial vortex develops in the channel symmetry axis. The flow in the horizontal plane is strongly deflected in the transverse channel direction, resulting in sediment entrainment at the pier sides. Further downstream, the flow separates from the pier resulting in the turbulent wake zone.

- Phase 2: The initial vortex disappears when the scour hole reaches the channel symmetry axis. The separation point migrates from the channel axis downstream along the pier perimeter, associated 
Fig. 3 Scour topography and streamline plots in the planes $Z_{S}=+0.50($ top $)$ and 0 (centre) at times $t=\mathbf{a} 60 \mathrm{~s}$ and b $86,400 \mathrm{~s}$; Scour hole topography (bottom); dotted line limit curve from where PIV data are not available because of sediment deposition (a)
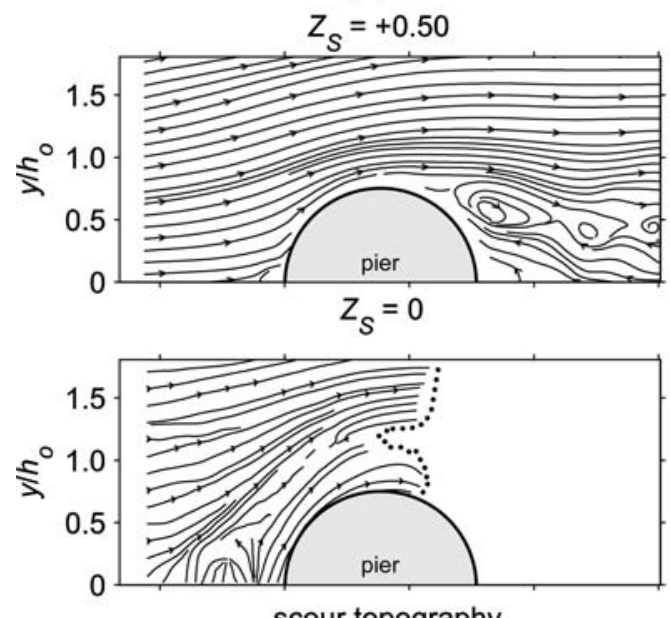

scour topography

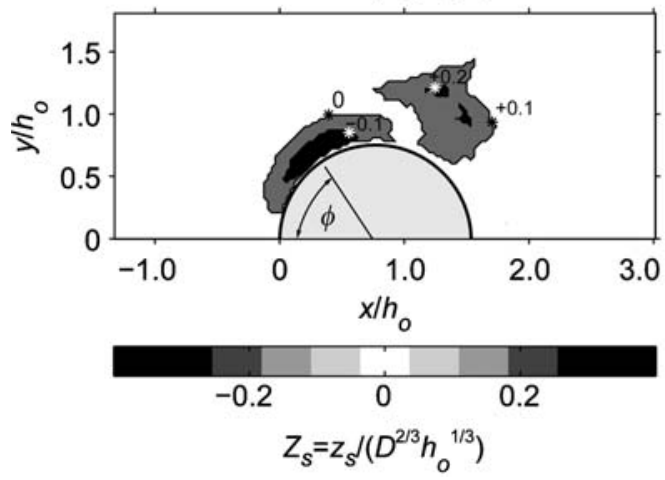

(b)
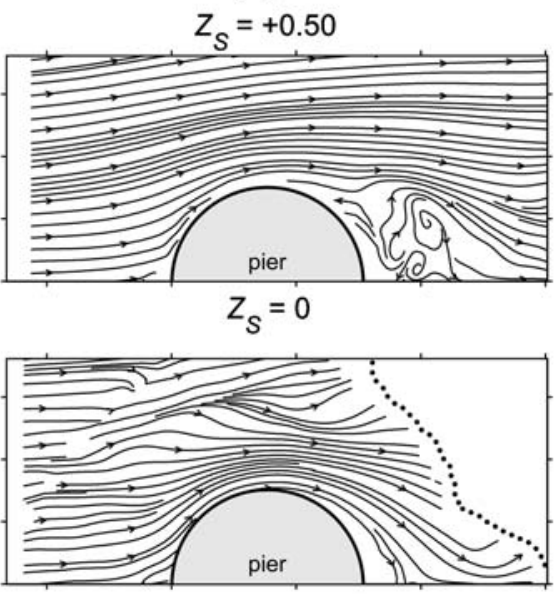

scour topography

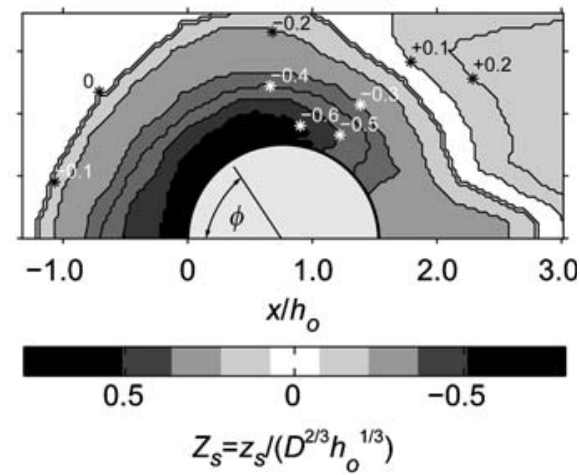

with a decreasing wake zone close to the sediment bed elevation.

- Phase 3: A scour inducing single horseshoe vortex establishes in the scour hole. The flow inside the scour hole is always attached to the pier perimeter and is comparable to Coanda flow.

- Phase 4: The horseshoe vortex system is fully developed. It consists of a primary vortex and one or even more secondary vortices; simultaneously the maximum scour depth migrates to the leading pier front. Because of the scour hole extension, the flow velocity around the pier immediately decreases and the scour advance eventually decelerates, resulting in the logarithmic scour depth increase. The main scour activity is concentrated to the pier front zone resulting from the fully developed main horseshoe vortex. The flow separation from the pier and the linked wake zone develop only near to the water surface, approximately for $Z_{S}>1 / 3$.

\subsection{Horseshoe vortex characteristics}

The following applies to the characteristics of the primary horseshoe vortex. Figure 4a shows a sketch of the vertical profile of the horizontal velocity component through the vortex centre including all relevant parameters. The upper abscissa is the horizontal coordinate $x$ whereas the lower relates to the dimensionless horizontal velocity component $v_{x} / V_{\mathrm{o}}$. On the left ordinate the vertical coordinate $z$ is plotted, whereas the normalized counterpart $\dot{z}_{v}=z+z_{S v}$ with $z_{S v}$ as the positive scour depth below the vortex centre (subscript $v$ for horseshoe vortex) is shown on the right. The dimensionless vertical coordinate $\dot{Z}_{v}$ is

$$
\dot{Z}_{v}=\frac{\dot{z}_{v}}{\left(z_{S v}+z_{v 0}\right)}
$$

with $z_{v 0}$ as the negative distance between the original sediment bed and the instantaneous vortex centre. The values $\dot{Z}_{v}=0$ and 1 refer to the instantaneous sediment surface below the vortex centre, and the vortex centre position, respectively. Based on the logarithmic description of the temporal scour evolution as proposed by Oliveto and Hager (2002), the dimensionless scour depth below the vortex centre is $Z_{S v}=z_{S v} / z_{R}$, with $z_{R}=\left(h_{o} D^{2}\right)^{1 / 3}$ as the reference length. It can be expressed as (Unger 2006) 
$Z_{S v}=2 \gamma \sigma^{-1 / 3} \cdot \mathrm{F}_{d}^{3 / 2} \cdot \log \left(T_{S} / T_{0}\right)$

and the dimensionless distance $Z_{\nu 0}=z_{\nu 0} / z_{R}$ as

$Z_{v 0}=-\gamma \sigma^{-1 / 3} \cdot \mathrm{F}_{d}^{3 / 2} \cdot \log \left(T_{S} / T_{0}\right)$.

Herein $\gamma=0.025$ is a constant, $\mathrm{F}_{d}=V_{o} /\left(\mathrm{g}^{\prime} d_{50}\right)^{1 / 2}$ is the approach flow densimetric particle Froude number with $\mathrm{g}^{\prime}=\left[\left(\rho_{s}-\rho\right) / \rho\right] \mathrm{g}$ as the reduced gravitational acceleration (where $\rho$ and $\rho_{s}$ are the fluid and sediment densities), $\sigma=\left(d_{84} / d_{16}\right)^{1 / 2}$ is the sediment non-uniformity, $T_{S}=t / t_{R}$ the dimensionless scour advance time with $t_{R}=z_{R} /\left[\sigma^{1 / 3} /\left(\mathrm{g}^{\prime} d_{50}\right)^{1 / 2}\right]$ as the reference time (Hager and Oliveto 2002), and $T_{0}=t_{0} /$ $t_{R}$ the dimensionless switching time between Phases 2 and 3. The latter expresses the duration from the start of an experiment to the development of the horseshoe vortex, therefore. It was found that (Unger 2006)

$$
T_{0}=0.25 \cdot \mathrm{F}_{t}^{-3 / 2}\left(z_{R} / d_{50}\right)
$$

Fig. 4 a Typical vertical profile of the horizontal velocity of the primary horseshoe vortex; b particle image including the schematic flow pattern

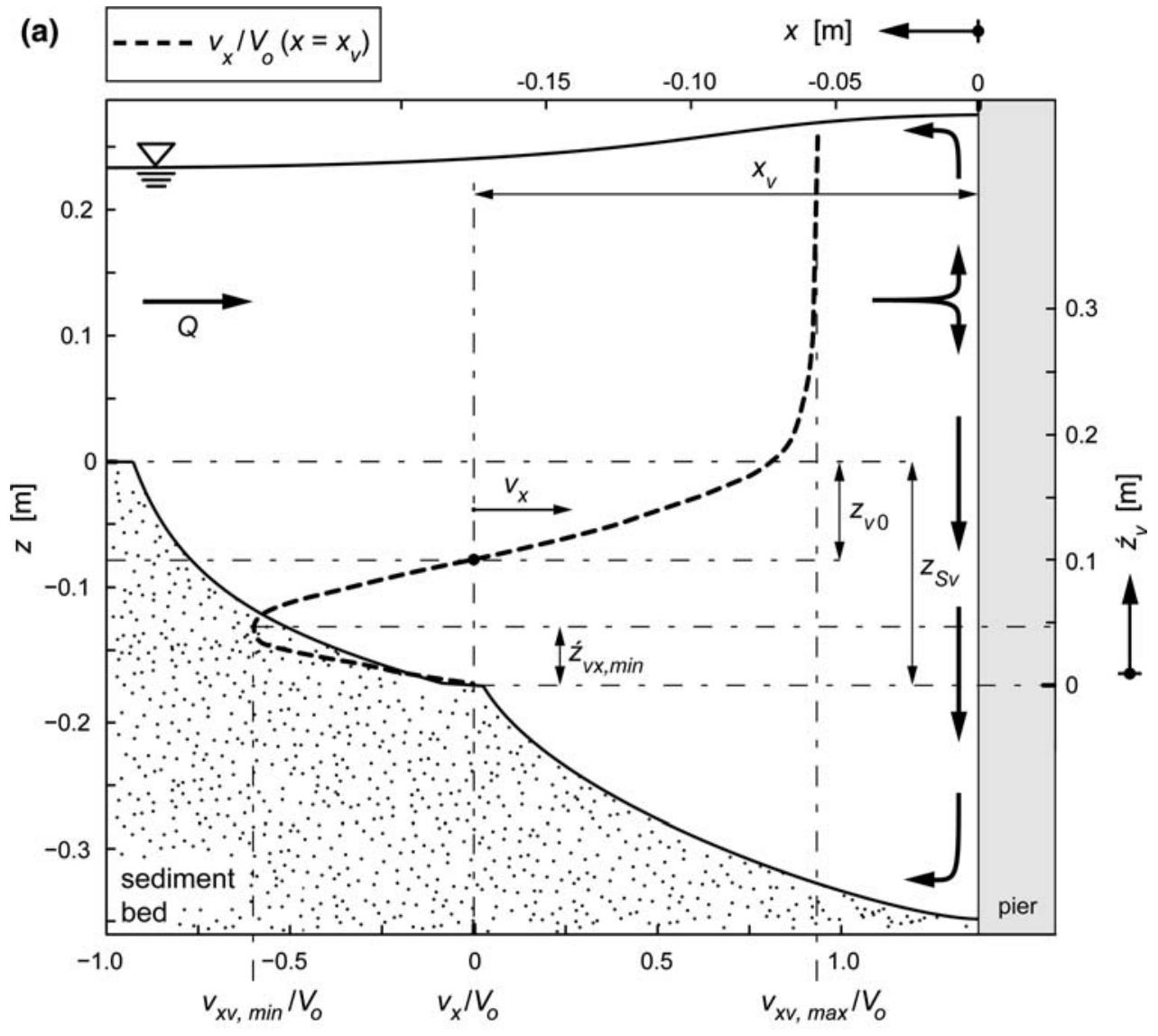

(b)

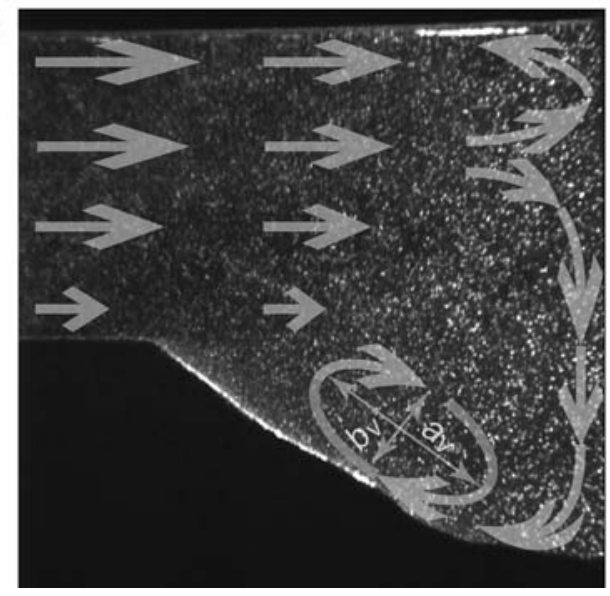


with $\mathrm{F}_{t}=V_{o} / V_{t}$ as the approach flow threshold Froude number and $V_{t}$ as approach flow threshold velocity (Oliveto and Hager 2005). Combining Eqs. 2 and 3 results in $Z_{v 0}=-2 Z_{S v}$; consequently, the horseshoe vortex centre is positioned at the constant elevation $Z_{S v} / 2$.

Figure 5 compares Eqs. 2 to 4 fitted as straight lines with the test data; the $\pm 25 \%$ intervals are added as dashed lines. In Fig. 5a and b the logarithm of the dimensionless time $T_{S} / T_{0}$ is plotted against the remaining parameters of Eqs. 2 and 3, respectively. Figure 5c presents the combined parameter $\mathrm{F}_{t}^{-3 / 2}\left(z_{R} / d_{50}\right)$ as abscissa versus the dimensionless switching time $T_{0}$, according to Eq. 4. For all three plots, the data scatter is approximately $\pm 30 \%$, an acceptable value in scour hydraulics. The dominant parameters in Eqs. 2 to 4 are $\mathrm{F}_{d}$ and $\mathrm{F}_{t}$, given their effect is at the power 1.5.

The normalized minimum horizontal velocity $v_{x v, \min } / V_{o}$ is below the horseshoe vortex centre close to the instantaneous sediment surface (Fig. 4a). A detailed data analysis yields (Unger 2006)

$v_{x v, \min } / V_{o}=-0.018 \cdot\left[\sigma^{1 / 2} \cdot\left(h_{o}^{2} D\right)^{1 / 3} / d_{50}\right]^{1 / 2} \cdot \log \left(T_{S} / T_{0}\right)$

According to Fig. $4 \mathrm{a}$ and Eq. 1 the dimensionless vertical position of the minimum horseshoe vortex velocity $\dot{Z}_{v x \text {, min }}=\dot{z}_{v x, \min } /\left(z_{S v}+z_{v 0}\right)$ can be described as

$\dot{Z}_{v x, \text { min }}=1-0.076 \cdot\left(z_{R} / d_{50}\right)^{1 / 4} \cdot \log \left(T_{S} / T_{0}\right)$.

Figure $6 \mathrm{a}$ and $\mathrm{b}$ compare Eqs. 5 and 6 with the test data as full circles in a semi-logarithmic plot for each run (Table 1). Herein, the abscissa represents the dimensionless time $T_{S} / T_{0}$ and the ordinate $v_{x v, \min } / V_{o}$ and $\dot{Z}_{v x \text {, min }}$, respectively. Nearly all the data are contained within the $\pm 25 \%$ margins. The vortex velocity $v_{x v}$, min $/ V_{o}$ and its geometric position $Z_{v x \text {, min }}$ can be estimated from Eqs. 5 and 6, therefore.

Fig. 5 a Normalized scour depth $Z_{S v} \cdot \sigma^{1 / 3} / \mathrm{F}_{d}^{3 / 2}$ with (solid line) Eq. 2, b normalized distance $Z_{v 0} \cdot \sigma^{1 / 3} / \mathrm{F}_{d}^{3 / 2}$ against relative time $T_{S} / T_{0}$ with (solid line) Eq. 3; c normalized time $T_{0}$ against $\mathrm{F}_{t}^{-3 / 2} \cdot z_{R} / d_{50}$ with (solid line) Eq. 4; (filled circle) test data; $R^{2}=\mathbf{a} 0.76, \mathbf{b} 0.73$ and $\mathbf{c} 0.79$ (a)

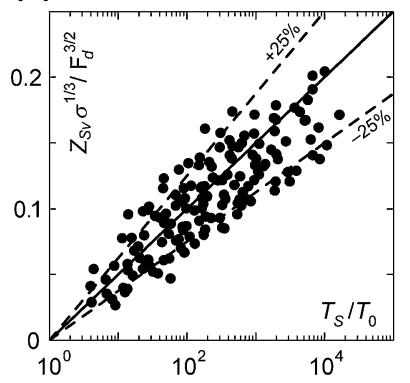

Based on the previously described characteristic horseshoe vortex parameters the velocity profile from the vortex centre to the instantaneous sediment bed may be derived. It has been demonstrated that scour inducing shear stresses occur only below the vortex centre (Unger 2006). Therefore, the velocity profile is exclusively determined in this region. The sought mathematical function $\mathrm{f}$ has to impose the following basic time-averaged boundary conditions:

(1) $\mathrm{f}\left(\dot{Z}_{v}=0\right)=0$, at the instantaneous sediment surface;

(2) $\mathrm{f}\left(\dot{Z}_{v}=1\right)=0$, in the vortex centre (Fig. 4a);

(3) $\mathrm{f}\left(\dot{Z}_{v x, \min }\right)=1$, position of the minimum horizontal horseshoe vortex velocity and

(4) $\mathrm{df} / \mathrm{d} \dot{Z}_{v x} \quad\left(\dot{Z}_{v x, \min }\right)=0$, minimum horizontal horseshoe vortex velocity.

The boundary conditions (1) and (2) specify the zeros of the function $\mathrm{f}\left(\dot{Z}_{v}\right)$, and (3) and (4) the local maximum of the function $f$. These boundary conditions are imposed by a combined quadratic and exponential function. The velocity profile $V_{x v}=v_{x v} / v_{x v}$, min $=\mathrm{f}\left(\dot{Z}_{v}\right)$ was found as (Unger 2006)

$V_{x v}=f_{1} \dot{Z}_{v} \cdot\left(1-\dot{Z}_{v}\right) \cdot \exp \left(f_{2} \dot{Z}_{v}\right)$.

Inserting (3) and (4) in Eq. 7 gives for the factors $f_{1}$ and $f_{2}$

$f_{1}=\left[\dot{Z}_{v x, \min } \cdot\left(1-\dot{Z}_{v x, \min }\right) \cdot \exp \left(f_{2} \dot{Z}_{v x, \min }\right)\right]-1$,

$f_{2}=\frac{\left[2 \cdot \dot{Z}_{v x, \min }-1\right]}{\left[\dot{Z}_{v x, \min } \cdot\left(1-\dot{Z}_{v x, \min }\right)\right]}$.

Inserting Eqs. 8 and 9 in Eq. 7 leads to the vertical velocity profile for arbitrary times, as shown in Fig. 7. The temporal variation of $\dot{Z}_{v x}$, min from Eq. 6 results in a variable velocity profile for each run and time. Figure 7 compares Eq. 7 with the observations for three runs and three times, namely: (1) At the start of

(b)

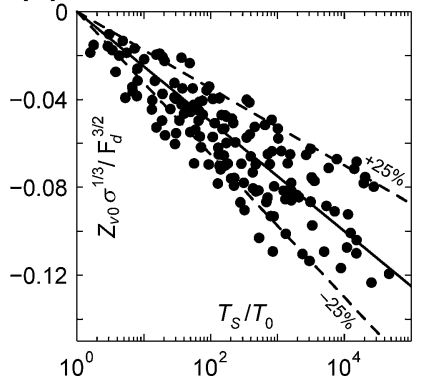

(c)

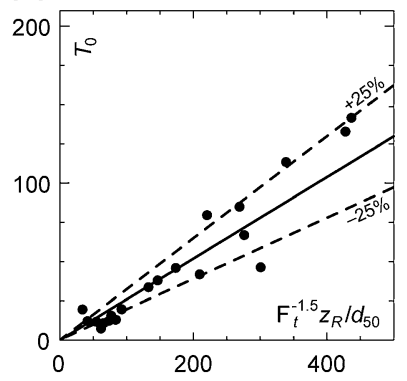


Fig. 6 Temporal evolution of a minimum horizontal velocity $v_{x v, \min } / V_{o}$ below the horseshoe vortex centre with (solid line) Eq. 5 and $\mathbf{b}$ its vertical position $\dot{Z}_{v x \text {, min }}$ with (solid line) Eq. 6; (filled circle) test data; a $0.56 \leq R^{2} \leq 0.94$ and $\mathbf{b} 0.68 \leq R^{2} \leq 0.88$
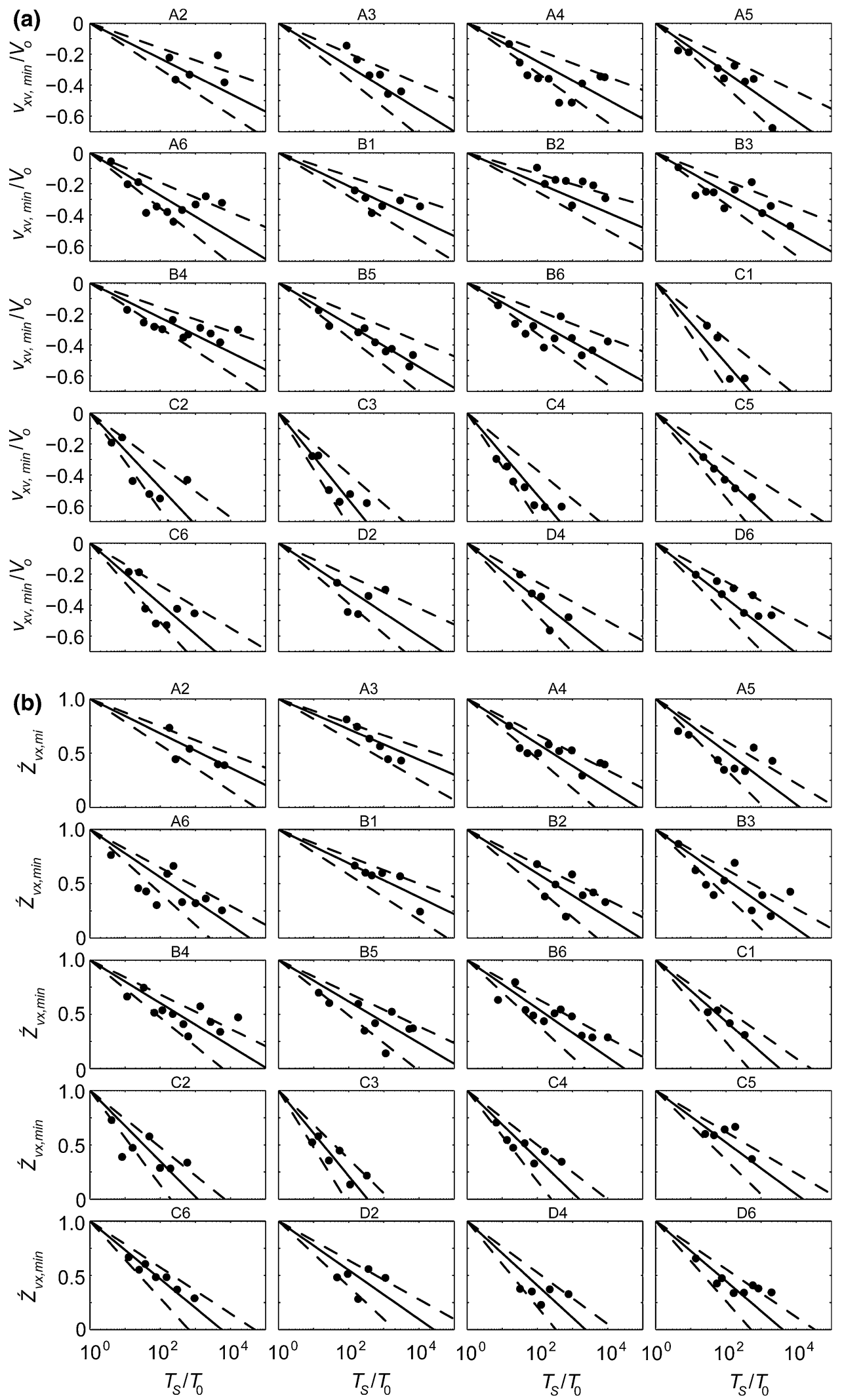
the horseshoe vortex, corresponding to the initiation of phase 3, (2) at the starting time of phase 4, and (3) at the test end. Figure 7 demonstrates that the velocity minimum migrates with increasing time toward the instantaneous sediment surface. Simultaneously the maximum velocity $v_{x v}$, min decreases with time (Fig. 6a), as was confirmed by visual observations.

From Fig. 4a, the velocity above the horseshoe vortex centre increases logarithmically to the maximum $v_{x v, \max }$ at the water surface (Unger 2006). With $|x|$ as the horizontal distance from the horseshoe vortex centre to the leading pier front, the normalized maximum horizontal velocity $v_{x v}$, max $/ V_{o}$ is (Unger 2006)

$v_{x v, \max } / V_{o}=1-0.057^{|x| / z_{R}}$

In Fig. 8 a the normalized maximum velocity $v_{x v, \max } / V_{o}$ is plotted against the normalized distance $|x| / z_{R}$. The continuous line represents Eq. 10, the full symbols the maximum velocities above the vortex centre and the open symbols the maximum velocities downstream of it. At the pier location $|x| / z_{R}=0$ this velocity tends to zero. Note the transition from the almost undisturbed approach flow to the pier-influenced zone from $|x| /$ $z_{R}=0.75$.

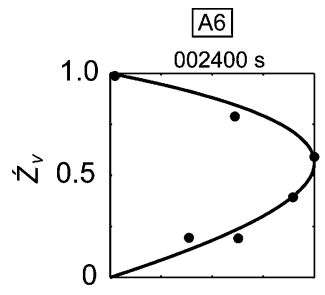

$015300 \mathrm{~s}$
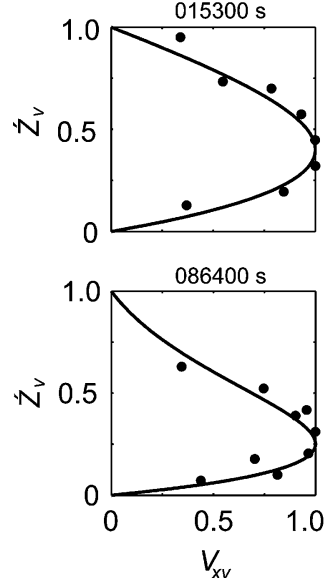

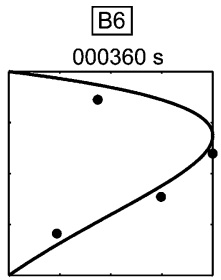

$002400 \mathrm{~s}$

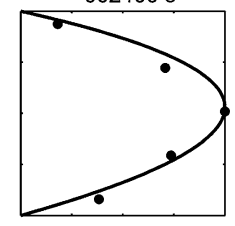

$028800 \mathrm{~s}$

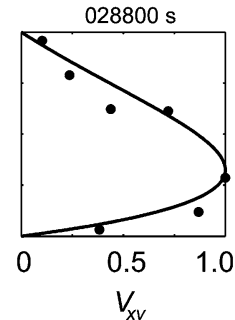

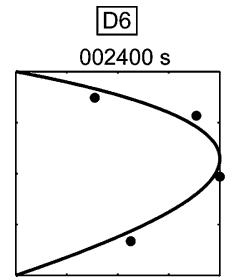

$014100 \mathrm{~s}$

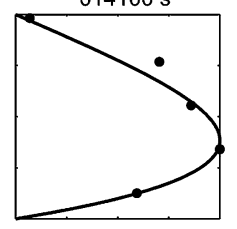

$086400 \mathrm{~s}$

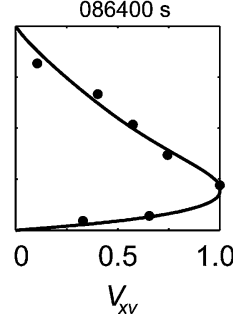

Fig. 7 Vertical velocity profiles below the horseshoe vortex centre for runs A6, B6 and D6 from phase 2 to phase 3 (top), during phase 3 (centre) and in phase 4 (bottom) with (solid line) Eq. 7, (filled circle) test data
Further, the distance $x_{v}$ between the pier front and the vortex centre was derived from the test data. Based on an almost circular vortex shape and on Eq. 2 the dimensionless distance $X_{v}=x_{v} / z_{R}$ was expressed as

$X_{v}=x_{v} / z_{R}=0.041 \cdot \sigma^{-1 / 3} \cdot \mathrm{F}_{d}^{3 / 2} \cdot \log \left(T_{S}\right)$.

Figure $8 \mathrm{~b}$ compares Eq. 11 with the test data in a semilogarithmic plot. Again, the scatter of the data is with $\pm 25 \%$ reasonable in scour hydraulics. The dominant term for the distance $x_{v}$ is the densimetric Froude number $\mathrm{F}_{d}$ followed by the reference length $z_{R}$.

The horseshoe vortex in the channel axis is elliptically shaped. With $a_{v}$ as the shorter and $b_{v}$ as longer ellipse axis, respectively the vortex diameter $d_{v}=\left(a_{v}+b_{v}\right) / 2$ and the elliptic vortex shape $a_{v} / b_{v}$ are (Fig. 4b)

$$
\begin{aligned}
& d_{v} / z_{R}=0.03 \cdot \sigma^{-1 / 2} \cdot \mathrm{F}_{t}^{-1 / 8} \cdot \mathrm{F}_{d}^{3 / 2} \cdot \log \left(T_{S} / T_{0}\right) \\
& \frac{a_{v}}{b_{v}}=\exp \left(\frac{z_{s}}{D}\right)
\end{aligned}
$$

The correlations of Eqs. 12 and 13 with the test data are considered below.

\subsection{Down-flow characteristics}

The characteristics of the vertically deflected flow in front of the pier were determined similar to the horseshoe vortex. A definition sketch including the used parameters, the notation and a typical example of the vertical flow velocity profile is given in Fig. 9. As stated previously the approach flow in front of the pier is divided in two components, namely the up-flow toward the water surface between (1) and (3), and the down-flow toward the sediment surface between (3) and (5) with the stagnation point (3) at jet impact. The governing agent of the horseshoe vortex and thus of the scour process is the down-flow. A parameter normalization between zero and one ensured a time-independent coordinate system. The dimensionless vertical down-flow (subscript $f$ for down-flow) coordinate $Z_{f}$ is

$Z_{f}=\frac{\left(z_{S}+z\right)}{\left(z_{S}+z_{f 0}\right)}$

with $z$ as the vertical coordinate measured from the original sediment surface, $z_{S} \geq 0$ as the scour depth according to Oliveto and Hager (2002) and $z_{f 0}$ as vertical distance between the stagnation point and the original sediment surface. The latter can be expressed as (Unger 2006) 


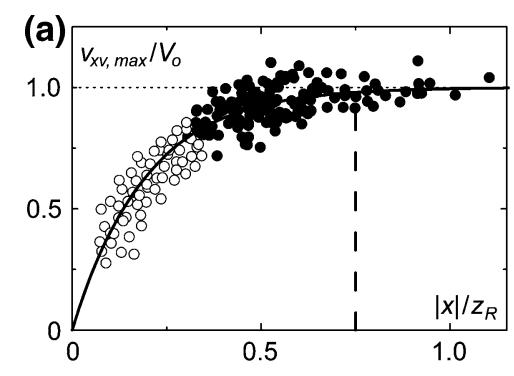

Fig. 8 a Decelerated maximum horizontal flow velocity $v_{x v}$, max $V_{o}$ toward the pier front $(|x|=0)$ against the normalized distance $|x| / z_{R}$ from the pier with (solid line) Eq. 10 and (dashed line) transition from pier to undisturbed approach flow zone, and

$\frac{z_{f 0}}{h_{o}}=0.79-4.84 \times 10^{-4}\left(\frac{z_{R}}{d_{50}}\right)$.

Let $z_{f \text {, max }}$ be the negative distance between the scour hole surface (5) and the position of the maximum vertical down-flow velocity (4). The normalized distance $Z_{f, \max }=\left(\mathrm{z}_{S}+z_{f, \max }\right) /\left(z_{S}+z_{f 0}\right)$ is then (Fig. 9)

$Z_{f, \max }=0.33+8.85 \times 10^{-4}\left(\frac{z_{R}}{d_{50}}\right)$.

The dimensionless maximum vertical down-flow velocity $v_{z f, \max } / V_{o}$ is

$\frac{v_{z f, \max }}{V_{o}}=-0.65+2.85 \times 10^{-4}\left(\frac{z_{R}}{d_{50}}\right)$.

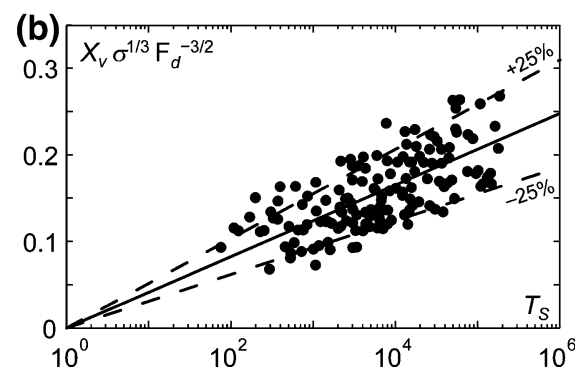

b temporal evolution of the normalized distance $X_{v} \cdot \sigma^{1 / 3} / \mathrm{F}_{d}^{3 / 2}$ between the pier front and the horseshoe vortex centre with (solid line) Eq. 11; (open circle, filled circle) test data; $R^{2}=\mathbf{a} 0.82$, b 0.70

Note that Eqs. 15 to 17 are independent of time, because the temporal effect is included in the temporally increasing scour depth $z_{S}$ (Eq. 14). Unger (2006) demonstrated a nearly constant evolution with time $t$ of the involved parameters $z_{f 0} / h_{o}, Z_{f, \max }$ and $v_{z f, \max } / V_{o}$. In Fig. 10 the corresponding mean values $z_{f 0} / h_{o}$, $Z_{f \text {, max }}$ and $v_{z f \text {, max }} / V_{o}$ are plotted versus $z_{R} / d_{50}$. The best fits represent Eqs. 15 to 17, shown as a straight lines with correlation coefficients $R^{2}=0.61,0.69$ and 0.81 , respectively.

From the knowledge of $Z_{f, \max }, v_{z f \text {, max }}$ and $z_{f 0}$ the vertical down-flow velocity profile can mathematically be derived. Again, this function requires zeros at the starting and at the end points together with a local maximum. Following the previously introduced con-
Fig. 9 Definition sketch of vertical velocity profile in front of the pier

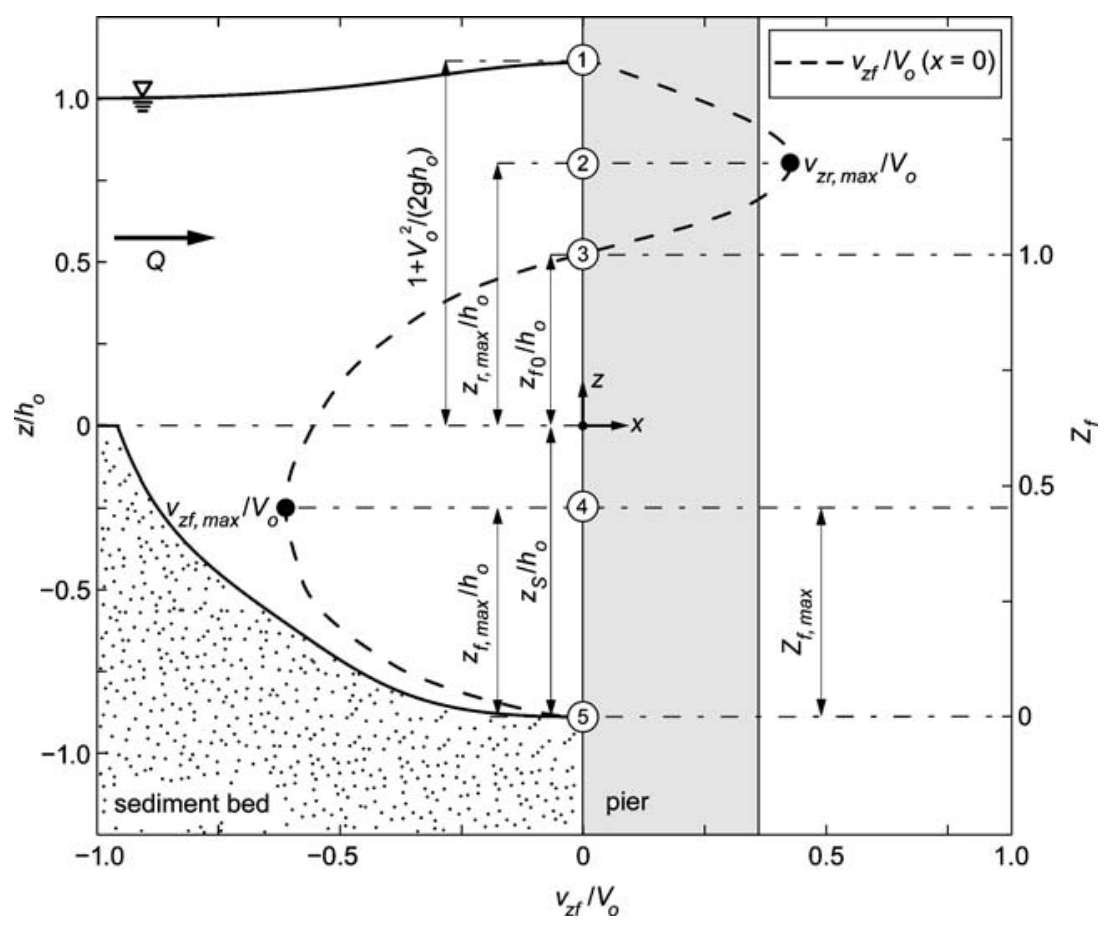


cept (Eqs. 7 to 9) the vertical velocity profile $V_{z f}=v_{z f}$ ' $v_{z f, \max }$ was formulated as (Unger 2006)

$V_{z f}=f_{1} Z_{f} \cdot\left(1-Z_{f}\right) \cdot \exp \left(f_{2} Z_{f}\right)$

with

$f_{1}=\left[Z_{f, \max } \cdot\left(1-Z_{f, \max }\right) \cdot \exp \left(f_{2} Z_{f, \text { max }}\right)\right]^{-1}$,

$f_{2}=\frac{\left[2 \cdot Z_{f, \text { max }}-1\right]}{\left[Z_{f, \max } \cdot\left(1-Z_{f, \max }\right)\right]}$.

Combining Eqs. 18 to 20 the down-flow velocity profile is specified. Figure 11 shows the results as continuous line in comparison with the present test data. The data scatter is again $\pm 30 \%$. Using the normalized coordinate from Eq. 14 allows describing the velocity profile independent of time, therefore.

Furthermore, the maximum up-flow velocity $v_{z r}$, max (2) and its position $z_{r, \max }$ were determined (Fig. 9). Figures 12 and 13 show the temporal evolution of the normalized velocity $v_{z r, \max } / V_{o}$ and the normalized position $z_{r \text {, max }} / h_{o}$, including its means. Again, no temporal effect may be detected. The best fits of the temporal mean values shown in Fig. 14 as a dashed and a straight line are

$\frac{v_{z r, \max }}{V_{o}}=0.23+4.83 \times 10^{-4}\left(\frac{z_{R}}{d_{50}}\right)$,

$\frac{z_{r, \max }}{h_{o}}=1.08-7.04 \times 10^{-4}\left(\frac{z_{R}}{d_{50}}\right)$

with $R^{2}=0.78$ and 0.67 , respectively. With a backwater height $z / h_{o}=1+V_{o}^{2} /\left(2 g h_{o}\right)$ (1) from energy conservation, the complete vertical velocity profile is thoroughly defined by Eqs. 14 to 22 (Fig. 9).

\subsection{Limitations}

The present results are subjected to the following limitations (see also Oliveto and Hager 2005):

- Rectangular and straight channel geometry with uniform roughness distribution,

- Element scoured is a circular cylinder with a relative diameter $D / B$ between 0.13 and 0.23 ,

- Steady approach flow conditions,

- Sediment size $d_{50}$ is smaller than 5-10 times the flow depth $h_{o}$ to avoid macro-roughness effects,

- Sediment size $d_{50}$ is larger than $0.8 \mathrm{~mm}$ to exclude viscous effects,

- Threshold Froude number $\mathrm{F}_{t}$ is smaller than 1.0 to ensure clear water conditions in the approach flow,

- Ratio of reference length $z_{R}$ and sediment size $d_{50}$ varies from 25 to 300 , and the dimensionless scour time $T_{S}$ is smaller than $2 \times 10^{5}$, corresponding to about 1 day, from the present experimental conditions.

\section{Discussion of results}

As mentioned, the quantitative flow characteristics around bridge piers have received limited attention, with most available researches restricted to selected test runs. In the following, the available literature data are compared with the present approach.

Melville and Raudkivi (1977) and Muzzammil and Gangadharaiah (2003) investigated the vortex diameter and its shape inside the scour hole. They related the relative vortex diameter $d_{v} / D$ to the instantaneous axial scour depth $z_{y=0} / D$. As previously described, the maximum scour depth $z_{S}$ migrates after a certain time from the pier sides to the pier front allowing for no reliable vortex diameter until the beginning of scour (a)

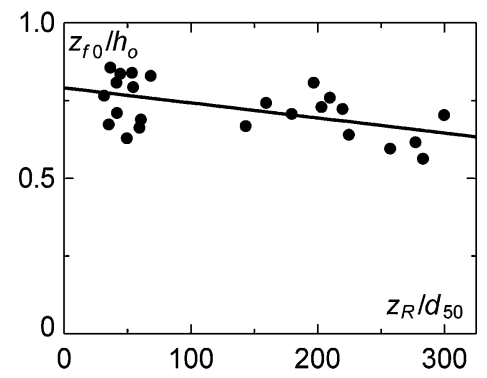

(b)

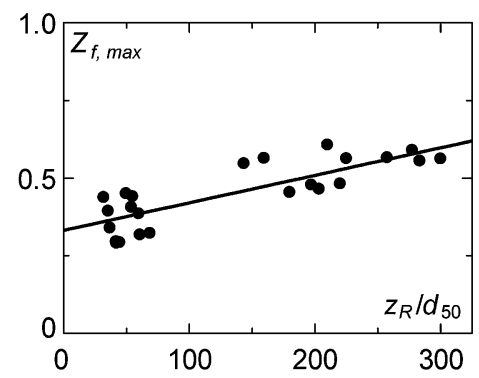

(c)

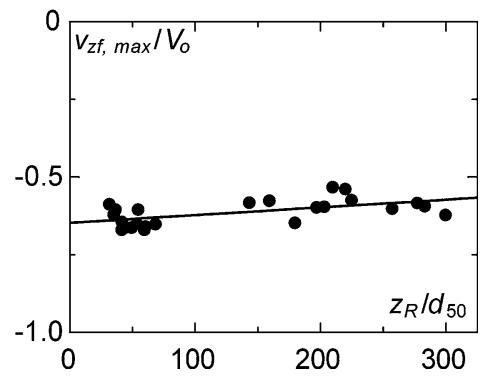

Fig. 10 Temporal means of a $z_{f 0} / h_{o}$ with (solid line) Eq. $15, \mathbf{b} Z_{f, \max }$ with (solid line) Eq. 16, and $\mathbf{c} v_{z f \text {, max }} / V_{o}$ with (solid line) Eq. 17 against $z_{R} / d_{50} ;$ (filled circle) test data; $R^{2}=\mathbf{a} 0.61$, b 0.69 and c 0.81 

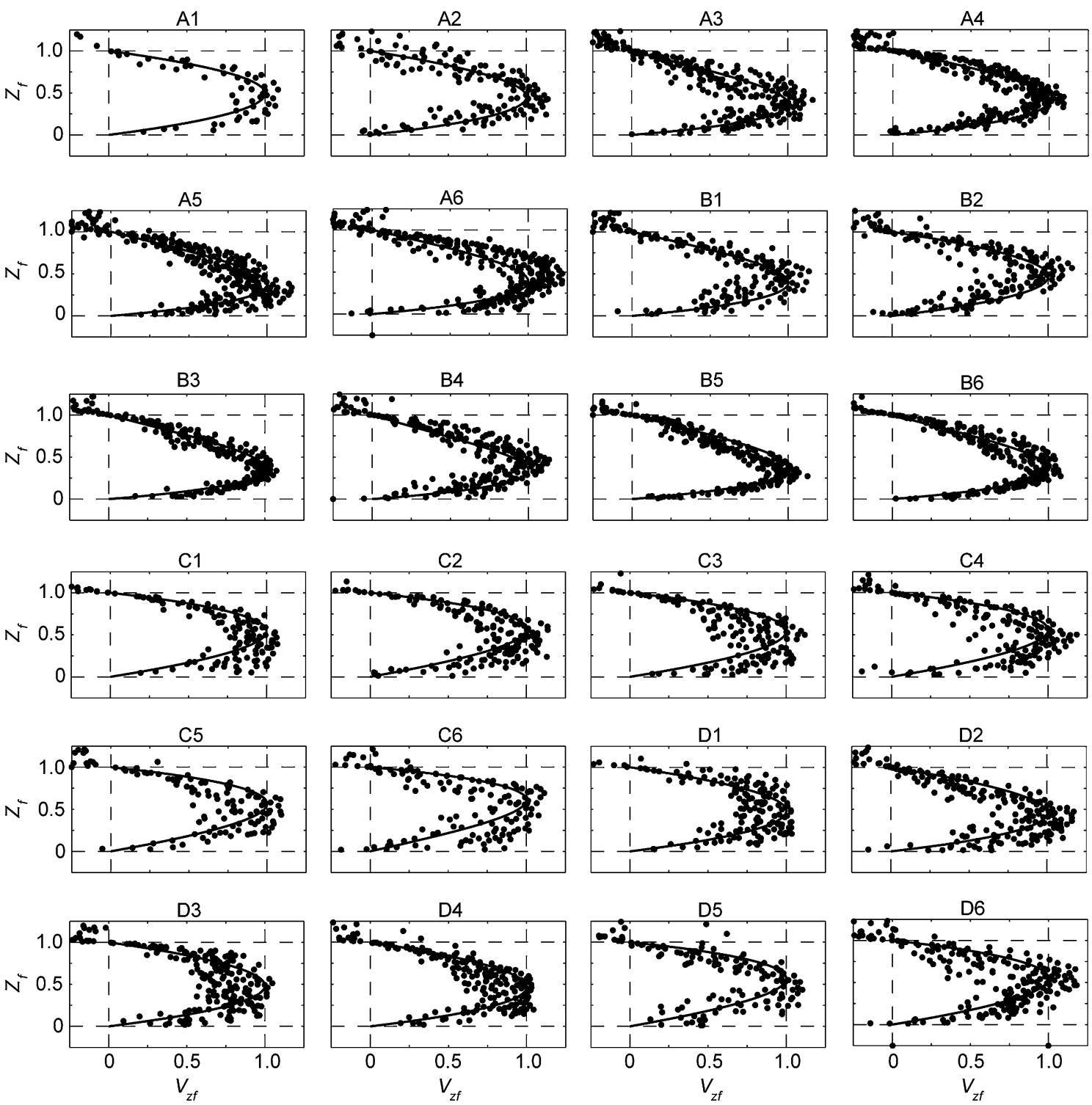

Fig. 11 Vertical down-flow velocity profile with (solid line) Eq. 18 and (filled circle) test data

phase 4. Figure 15a compares Muzzammil and Gangadharaiah's linear approach with the present test data and those of Raudkivi and Melville, resulting in a good overall agreement. Figure $15 \mathrm{~b}$ shows the predicted vortex shape expressed with $a_{v} / b_{v}$ using Eq. 13 as a continuous line. The scatter is about $\pm 25 \%$ except for the initial scour data of Muzzammil and Gangadharaiah relating always to the scour depth at the pier front.

Muzzammil and Gangadharaiah described the minimum horseshoe vortex velocity $v_{x v}$, min $/ V_{o}$ also as a function of the scour depth. Due to the incomplete published experimental conditions no direct data check was possible. However, a qualitative comparison results in considerable deviations (Unger and Hager $2005 \mathrm{~b})$. The present approach indicates values of $-0.1 \leq v_{x v}, \min / V_{o} \leq-0.6$ as compared to minimum velocities of $v_{x v, \min } / V_{o}=-1.6$. Melville and Raudkivi (1977), Sarker (1998) and Graf and Istiarto (2002) found with $v_{x v}$, min $/ V_{o}=-0.4,-0.8$ and -0.6 , respectively, similar results as proposed here. Roulund et al. (2005) determined values larger than -1.0 from numerical and experimental investigations.

Figure 16 shows the predicted down-flow velocity profiles from Eq. 18 in comparison with the test data of Graf and Istiarto (2002), Ahmed and Rajaratnam (1998) and Sarker (1998). The diagrams demonstrate an overall excellent agreement except for Sarker (1998). Close to the instantaneous sediment surface the data correlate with the present approach, whereas the predictions are systematically overestimated above the velocity maximum. Sarker observed no stagnation point, thus the vertical velocity is always directed 

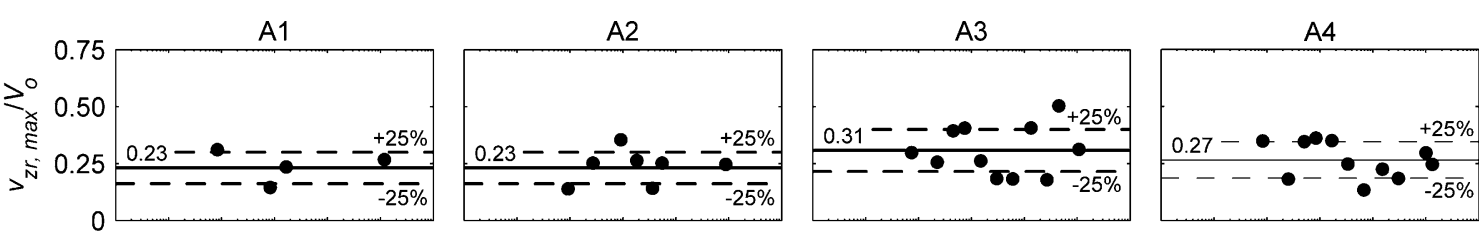
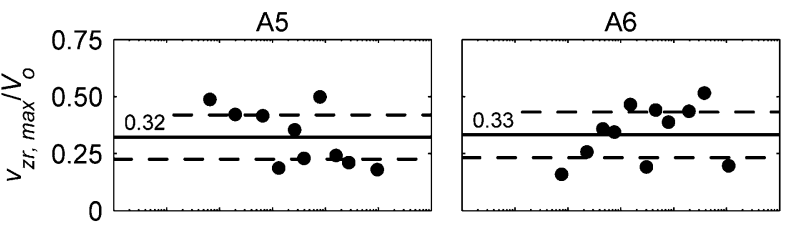

B1
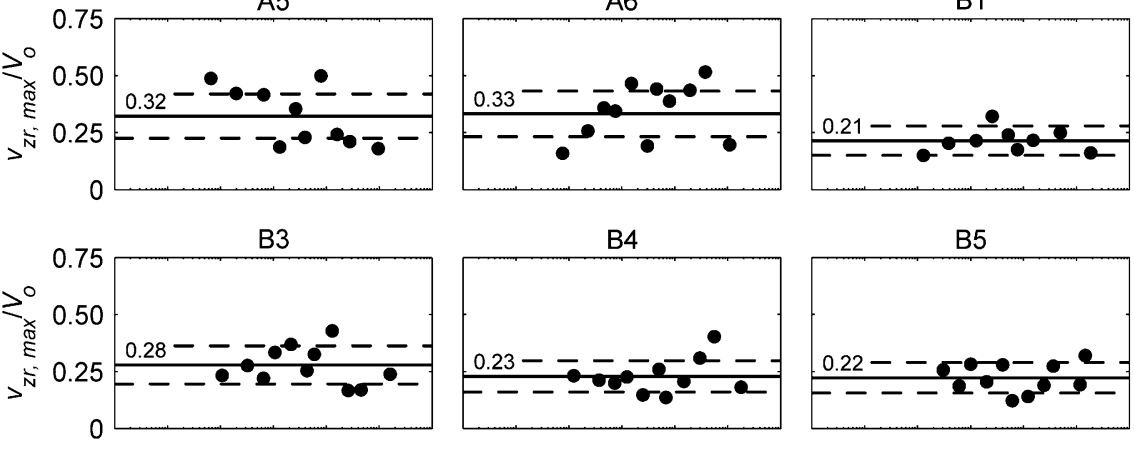

C1
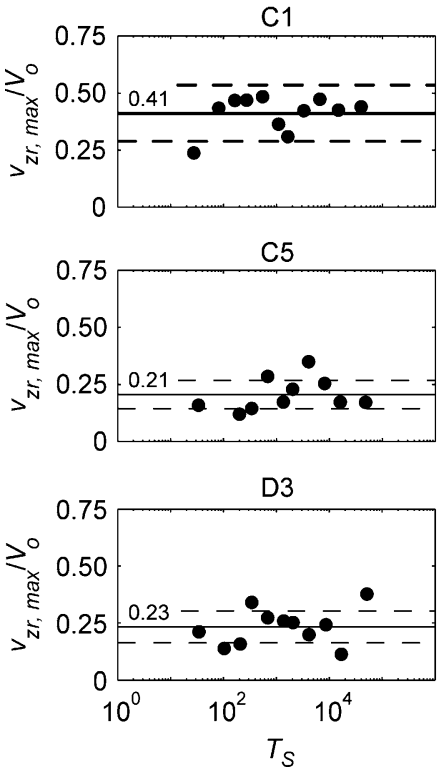

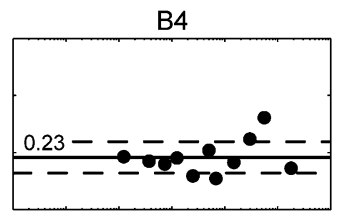

$\mathrm{C} 2$

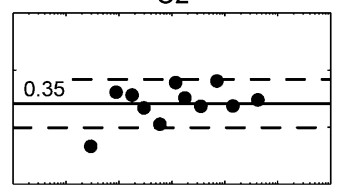

C6

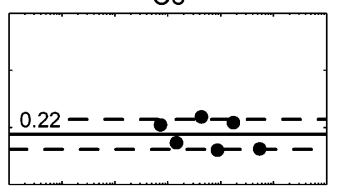

D4

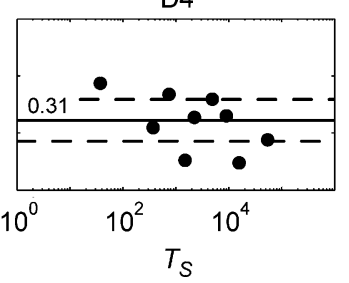

B5

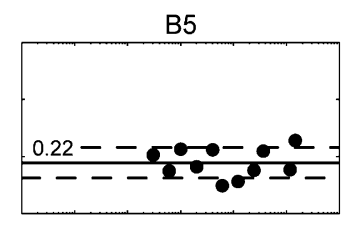

C3

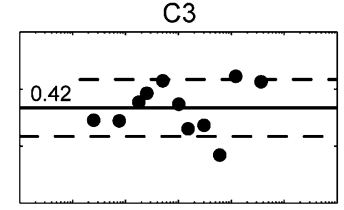

D1

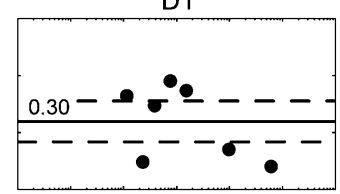

D5

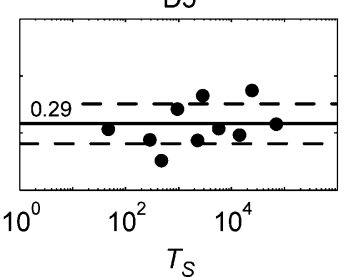

B2

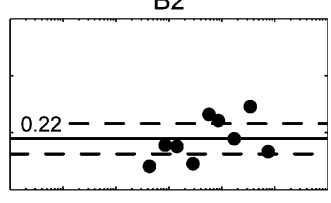

B6

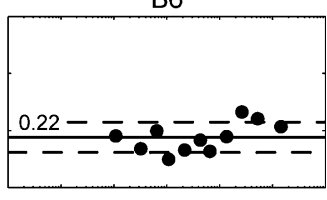

C4

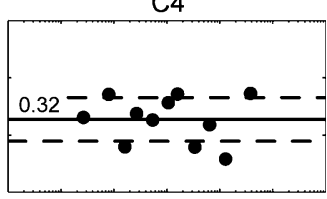

D2

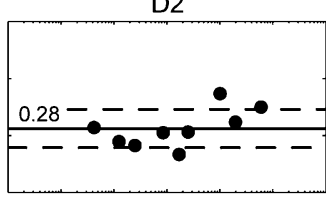

D6

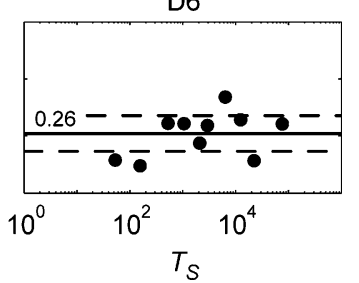

Fig. 12 Maximum vertical up-flow velocity $v_{z r, \max } / V_{o}$ versus dimensionless scour time $T_{S}$ with (solid line) Eq. 21 and (filled circle) test data; $0.58 \leq R^{2} \leq 0.89$

toward the sediment surface. This phenomenon was not described so far and seems to be physically impossible. Sarker's intrusive ADV probe might have caused this failure.

\section{Conclusions}

The temporal evolution of the spatial flow field around a sediment embedded circular bridge pier was investigated in a physical laboratory model based on the Froude similitude thereby using a large-scale PIV setup. The present results relate to two fundamental flow features, namely the horseshoe vortex and the downflow:
- The presence of a cylindrical bridge pier results in: (1) stagnation point, (2) up-flow, along with (3) a surface recirculation, (4) down-flow, (5) the initial vortex during scour phase 1 , and later (6) the horseshoe vortex system. In the horizontal planes (7) a separation from the pier sides, (8) a wake zone downstream of the pier and (9) singularities inside the scour hole were detected.

- These flow features proceed in four principal phases, from scour entrainment laterally from the pier generating the initial vortex at the pier front to the advanced scour process characterized by the fully developed horseshoe vortex system. Correspondingly, the horizontal flow pattern close to the scour 

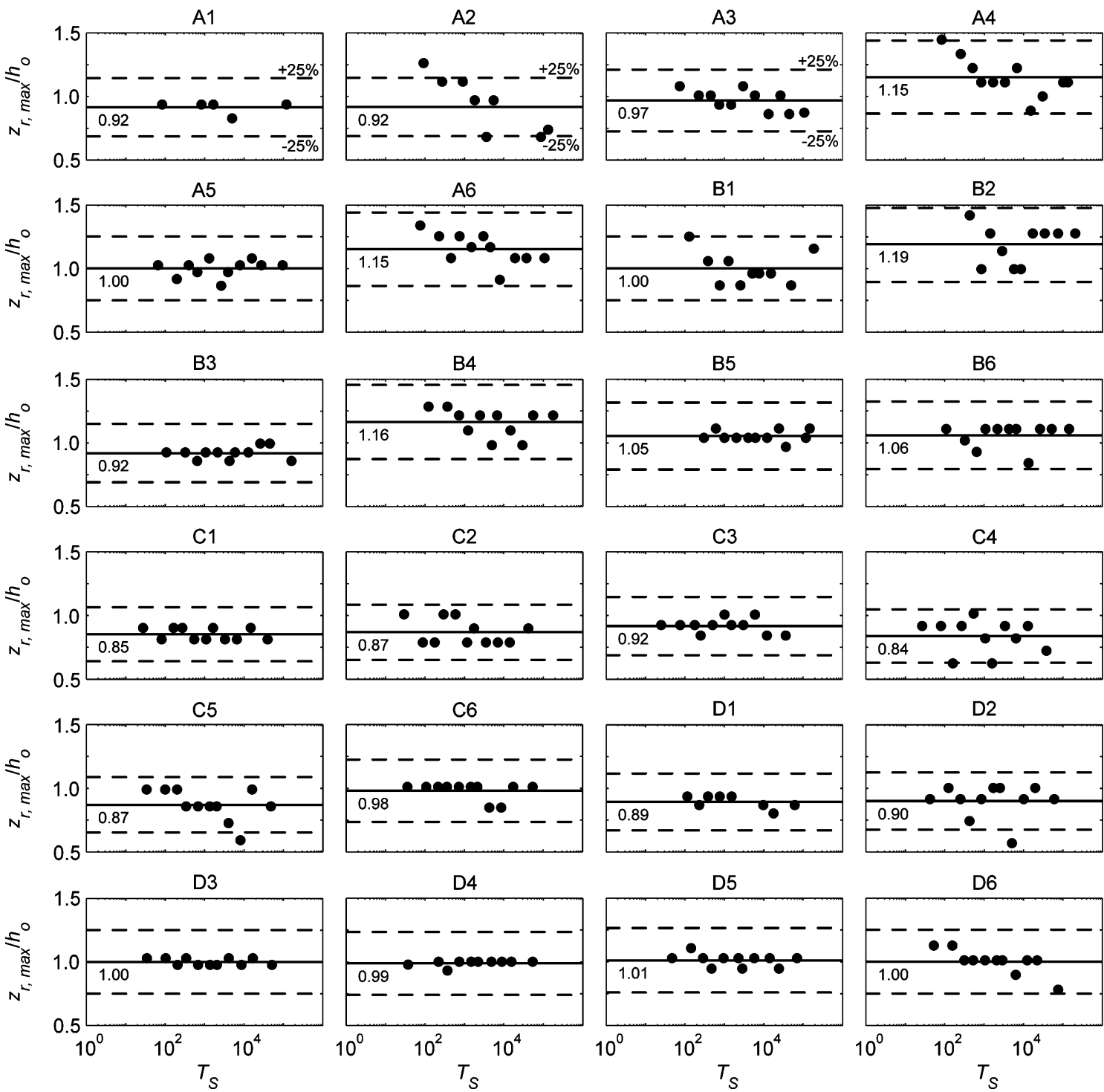

Fig. 13 Vertical position $z_{r, \max } / h_{o}$ of the maximum up-flow velocity versus dimensionless scour time $T_{S}$ with (solid line) Eq. 21 and (filled circle) test data; $0.58 \leq R^{2} \leq 0.89$

hole develops from flow separation from the pier to flow attached to it, similar to the Coanda effect.

- The horseshoe vortex inside the continuously increasing scour hole and the vertical jet at the pier front are the governing scour agents; the respective velocity profiles were investigated and expressions are given based on a detailed data analysis.

- The main effects along the pier front, namely the down-flow, the stagnation point and the up-flow, do not explicitly vary with time, because their temporal evolutions are expressed with the normalization parameters. The velocities and the geometric posi- tions are governed by the approach flow conditions, the reference length $z_{R}$ and the median sediment size $z_{R} / d_{50}$.

- The primary horseshoe vortex develops with time. Its velocity profile is governed by the pier diameter $D$, the approach flow depth $h_{o}$, the relative median sediment size $z_{R} / d_{50}$ and the densimetric particle Froude number $\mathrm{F}_{d}$. The vortex size and the vortex shape were derived as a function of time.

- The results of the present study were compared with the available literature data. Limitations relating to the present work were formulated by Oliveto and Hager (2005). 


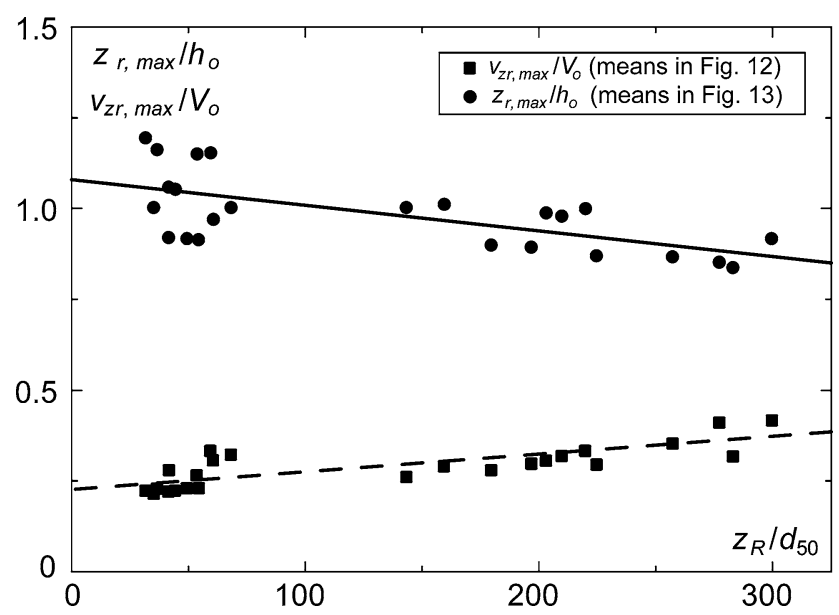

Fig. 14 Mean values of the maximum up-flow velocity $v_{z r, \max } / V_{o}$ (bottom) from Fig. 12 and its vertical position $z_{r, \max } / h_{o}(t o p)$ from Fig. 13 against $z_{R} / d_{50}$
- The present test data and the proposed approach are a contribution to both pier scour experimentation and the development and validation of numerical models in scour hydraulics.

Acknowledgments The first author would like acknowledge the financial support from the Swiss National Science Foundation, Contract Number NF 2-77095-01.

\section{Appendix 1}

The present research project was based on the halfchannel set-up of the hydraulic model. There are essentially three reasons for this procedure: (1) Optical quality of data near the channel window is superior to the mid-channel location, given the small amount of dust contained always in water flowing over a sediment (a)

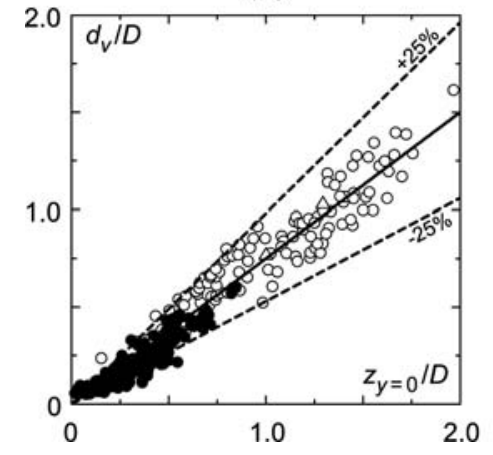

(b)

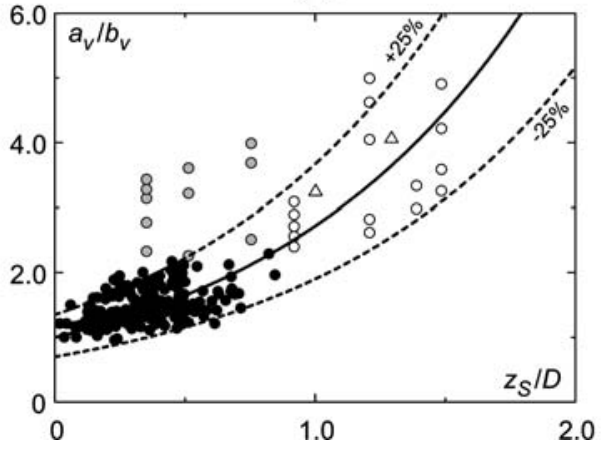

(open circle, light shaded circle) Muzzammil and Gangadharaiah (2003) scour depths at the pier front in phase 4 and prior to phase 4 , respectively, and (open triangle) Melville and Raudkivi (1977)

Fig. 15 Comparison of a the linear horseshoe vortex diameter $d_{v} / D=0.75 z_{y=0} / D$ and $\mathbf{b}$ horseshoe vortex shape $a_{v} / b_{v}$ with (solid line) Eq. 13; (dark shaded circle) test data of present study,

(a)

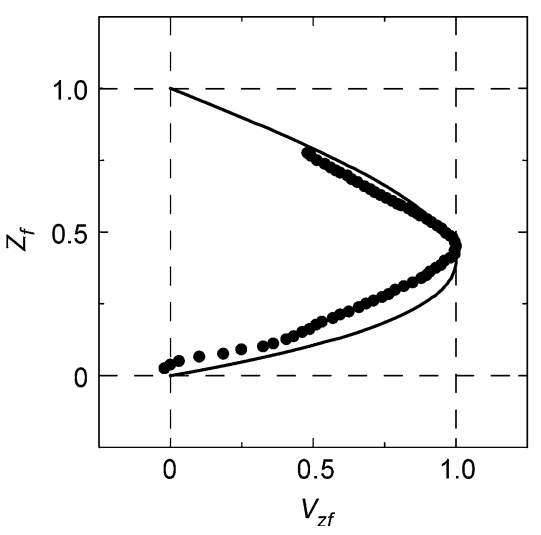

(b)

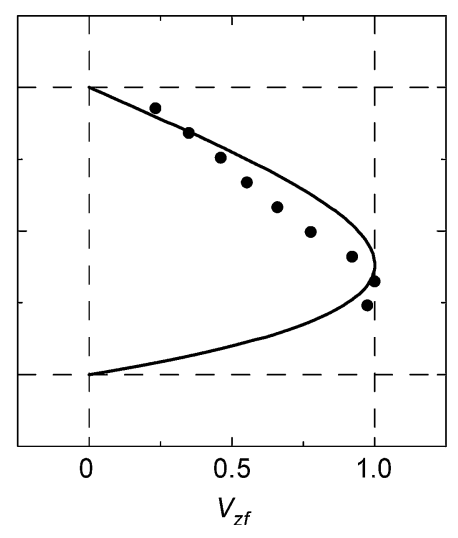

(c)

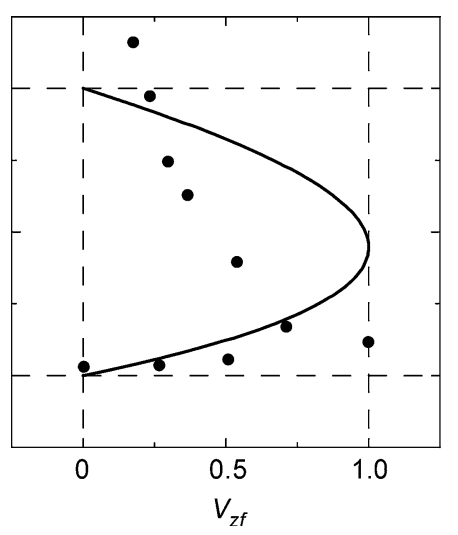

Fig. 16 Comparison of vertical down-flow velocity profile according to (solid line) Eq. 18 with (filled circle) experimental data of a Graf and Istiarto (2002), b Ahmed and Rajaratnam (1998) and c Sarker (1998) 
Fig. 17 Temporal evolution of depth-averaged transverse velocity distribution at $x / D=\mathbf{a}-2 / 3$ (run D1) and b $-7 / 10$ (run D6) (a)

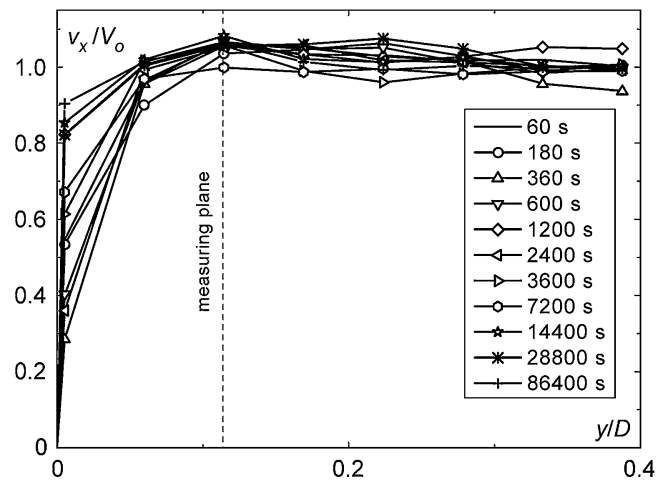

(b)

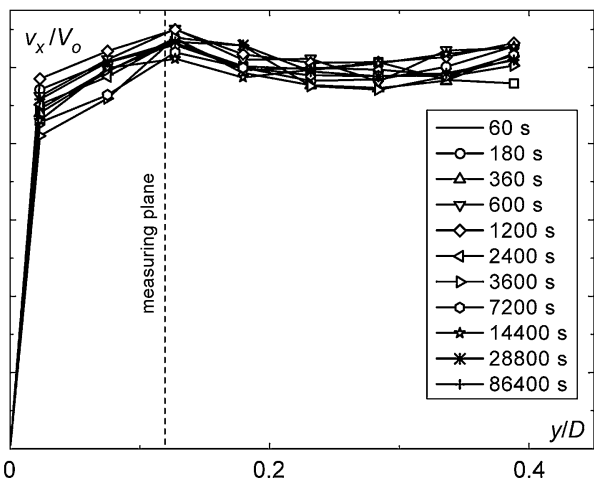

bed, (2) no problems with the scour hole and deposition topography when collecting data lower than the instantaneous sediment elevation, and (3) artificial increase of hydraulic model by a factor of 2 , resulting in a better resolution quality of the PIV test data. However, this set-up also involved disadvantages resulting from the boundary layer along the channel wall. Therefore, it was of concern to demonstrate that the streamwise 'measuring plane' of the present research was out of the influence zone of the turbulent boundary layer.

Figure 17 shows depth-averaged velocity profiles $v_{x} / V_{o}(y / D)$ with $v_{x}$ as the streamwise velocity component and $y$ as the transverse coordinate measured from the channel glass wall for two typical tests. It may be observed for these and the other tests that the 'measuring plane' adopted in the present research was located fully within the central flow portion, where boundary layer effects are small. The minimum distance of the measuring plane relative to the pier diameter was established from preliminary observations. For the pier diameters adopted in this research distances $20 \leq y \leq 40 \mathrm{~mm}$ were used. Accounting for these limitations, the previously listed advantages resulting from a half-model set-up apply.

\section{References}

Achenbach E (1968) Distribution of local pressure and skin friction around a circular cylinder in cross-flow up to $\operatorname{Re}=5 \cdot 10^{6}$. J Fluid Mech 34(4):625-639

Ahmed F, Rajaratnam N (1998) Flow around bridge piers. J Hydraulic Eng 124(3):288-300

Ahmed F, Rajaratnam N (2000) Observation on flow around bridge abutments. J Eng Mech 126(1):51-59

Baker CJ (1979) Laminar horseshoe vortex. J Fluid Mech 95(2):347-367

Baker CJ (1980) The turbulent horseshoe vortex. J Wind Eng Ind Aerodyn 6(1-2):9-23

Baker CJ (1985) The position of points of maximum and minimum shear-stress upstream of cylinders mounted normal to flat plates. J Wind Eng Ind Aerodyn 18(3):263-274
Barbhuiya AK, Dey S (2004) Measurement of turbulent flow field at a vertical semicircular cylinder attached to the sidewall of a rectangular channel. Flow Meas Instrum 15(2):87-96

Batchelor GK (1967) An introduction to fluid dynamics. Cambridge University Press, Cambridge

Dargahi B (1989) The turbulent flow field around a circular cylinder. Exp Fluids 8(1):1-12

Eckerle WA, Langston LS (1987) Horseshoe vortex formation around a cylinder. J Turbomach 109(1):278-285

Graf WH, Istiarto I (2002) Flow pattern in the scour hole around a cylinder. J Hydraulic Res 40(1):13-20

Graf WH, Yulistiyanto B (1998) Experiments on flow around a cylinder: The velocity and vorticity fields. J Hydraulic Res 36(4):637-653

Hager WH, Oliveto G (2002) Shields' entrainment criterion in bridge hydraulics. J Hydraulic Eng 128(5):538-542

Hager WH, Unger J, Oliveto G (2002) Entrainment criterion for bridge piers and abutments. In: Bousmar D, Zech Y (eds) River Flow 2002, 2:1053-1058, A.A. Balkema, Lisse

Johnson KR, Ting FCK (2003) Measurements of water surface profile and velocity field at a circular pier. J Eng Mech 129(5):502-513

Lhermitte R, Lemmin U (1994) Open-channel flow and turbulence measurement by high-resolution Doppler sonar. J Atmos Oceanic Technol 11(5):1295-1308

Melville BW, Coleman SE (2000) Bridge scour. Water Resources Publication, Highlands Ranch

Melville BW, Raudkivi AJ (1977) Flow characteristics in local scour at bridge piers. J Hydraulic Res 15(4):373-380

Muzzammil M, Gangadharaiah T (2003) The mean characteristics of horseshoe vortex at a cylindrical pier. J Hydraulic Res 41(3):285-297

Oliveto G, Hager WH (2002) Temporal evolution of clear-water pier and abutment scour. J Hydraulic Eng 128(9):811-820

Oliveto G, Hager WH (2005) Further results to time-dependent local scour at bridge elements. J Hydraulic Eng 131(2):97105

Pogozelski EM, Katz J, Huang TT (1997) The flow structure around a surface piercing strut. Phys Fluids 9(5):1387-1399

Qadar A (1981) The vortex scour mechanism at bridge piers. Proc ICE Res Theory 71(3):739-757

Raffel M, Willert CE, Kompenhans J (1998) Particle image velocimetry—a practical guide. Springer, Berlin Heidelberg New York

Roulund A, Sumer BM, Fredsoe J, Michelsen J (2005) Numerical and experimental investigation of flow and scour around a circular pile. J Fluid Mech 534:351-401 
Sarker MA (1998) Flow measurement around scoured bridge piers using Acoustic-Doppler Velocimeter (ADV). Flow Meas Instrum 9(4):217-227

Schlichting H, Gersten K (1997) Grenzschicht-Theorie. Springer, Berlin Heidelberg New York

Thwaites B (1960) Incompressible aerodynamics. University Press, Oxford

Unger J (2006) Strömungscharakteristika um kreiszylindrische Brückenpfeiler - Anwendung von Particle Image Velocimetry in der Kolkhydraulik (in German). PhD Thesis 16557, ETH: Zurich

Unger J, Hager WH (2005a) Spatial and temporal scour features of circular bridge piers. In: Jun BH et al. (eds) 31. IAHR Congress, 5122-5131, KWRA, Seoul
Unger J, Hager WH (2005b) Discussion to the mean characteristics of horseshoe vortex at a bridge pier. J Hydraulic Res 43(5):585-588

Unger J, Hager WH (2006a) Riprap failure at circular bridge piers. J Hydraulic Eng 132(4):354-362

Unger J, Hager WH (2006b) Temporal flow evolution of sediment embedded circular bridge piers. In: Ferreira RML et al. (eds) River Flow 2006, 1:729-739, Taylor \& Francis Group, London 